\title{
Energy Affordability in the EU: The Risks of Metric Driven Policies
}

\author{
David Deller ${ }^{\mathrm{a}}$
}

${ }^{a}$ Centre for Competition Policy, University of East Anglia, Norwich Research Park, Norwich, Norfolk, United Kingdom, NR4 7TJ

Corresponding author contact details: email: david.deller@uea.ac.uk,Tel: 01603591617

12 December 2017

\begin{abstract}
This paper provides a pan-EU mapping of energy affordability using energy expenditure shares. Large variations in energy expenditure shares are identified, with the shares being significantly higher in New Member States than the EU15. First, these variations indicate that a single expenditurebased pan-EU fuel poverty metric is problematic; there is a trade-off between a metric identifying households in most need within individual Member States and one identifying households in a similar position across Member States. Second, household-level data from the UK, France and the Republic of Ireland are used to simulate the impact of 'policy interventions', involving energy expenditure reductions or income increases, on the recorded rate of fuel poverty. These simulations highlight that emphasising high-level fuel poverty metrics may distort policymakers' choices towards improving the 'picture' of fuel poverty rather than maximising welfare improvements. Robust impact assessments identifying the fuel poverty interventions which deliver the greatest welfare increases for a given cost offer a better means of policy evaluation.
\end{abstract}

Keywords: fuel poverty, energy affordability, expenditure shares

\footnotetext{
${ }^{1}$ This paper is a revised version of Deller (2016) which drew evidence from a report commissioned by the Centre on Regulation in Europe (CERRE). The report, Deller and Waddams (2015a), is available at: http://www.cerre.eu/sites/cerre/files/Affordability FinalReport.pdf (last accessed 29/8/17)
} 
Funding: This work was supported by Microsoft, EDF Energy, the Utility Regulator Northern Ireland and E-Control, the Austrian energy regulator, through the Centre on Regulation in Europe (CERRE).

\section{Introduction ${ }^{2}$}

Energy affordability has become an increasingly important issue in the $\mathrm{EU}^{3}$ with CEER-BEUC's 2020 Vision for Europe's Energy Customers ${ }^{4}$ including 'Affordability' as one of its four core principles to which energy regulators should adhere. There is also increased focus on energy poverty at the EU level with the establishment of The Energy Poverty Taskforce ${ }^{5}$ and the European Energy Poverty Observatory ${ }^{6}$ in 2016. The present paper expands the discourse on energy/fuel poverty ${ }^{7}$ towards the wider topic of energy affordability and the distribution of energy market outcomes across EU households. While fuel poverty is defined as "the phenomenon whereby a household struggles to afford adequate (energy) services" ${ }^{8}$, the present paper assesses wider variations in the extent to which energy services are more or less affordable across household groups and Member States (MS). Here, fuel poverty is seen as a notable subset of the energy affordability topic. ${ }^{9}$

\footnotetext{
${ }^{2}$ Abbreviations: Member State (MS); energy expenditure share (ENEXShr); New Member State (NMS); energy expenditure (ENEX); percentage of households with an energy expenditure exceeding 10\% (ENEX10); Low Income-High Cost (LIHC); European Union Statistics on Income and Living Conditions (EU-SILC); Republic of Ireland (Rol)

${ }^{3}$ Thomson et al. (2016) document this increasing attention.

${ }^{4}$ See CEER (2014).

${ }^{5}$ Established at the European Policy Centre, see: http://www.epc.eu/prog forum.php?forum id=67\&prog id=8 (last accessed 29.8.17)

${ }^{6}$ Established at Manchester University, see: http://www.mui.manchester.ac.uk/cure/research/projects/euroenergy-poverty-observatory/ (last accessed 29.8.17)

${ }^{7}$ The terms "energy" and "fuel" have the same meaning in this paper, i.e. all fuel sources used within the home.

${ }^{8}$ See section 2.1, pp. 564, Thomson and Snell (2013).

${ }^{9}$ While some may argue the fuel poor are automatically 'vulnerable', it is probably more useful to consider fuel poverty and vulnerability as distinct topics, i.e. someone can be fuel poor without being vulnerable and vice versa. For example, Ofgem, the UK energy regulator, does not have a statutory duty regarding the fuel poor, but does have an explicit legal duty to consider the interests of consumers who are of pensionable age, disabled, chronically sick, on low incomes or live in rural areas, see Ofgem (2015). The current paper's focus is affordability rather than vulnerability.
} 
First, the paper maps differences in energy affordability across the EU using energy expenditure share (ENEXShr) data thereby complementing the existing literature which utilises European Union Statistics on Income and Living Conditions (EU-SILC) ${ }^{10}$ to compare households' self-reported assessments of affordability. The average ENEXShr data presented in section 5.1 emphasises a striking difference in energy affordability between the EU15 and New Member States (NMS). In 2010, the average ENEXShr across the EU15 was $4.6 \%$, but among NMS it was $10.9 \%$.

Second, the paper analyses individual household-level data from the UK, France and the Republic of Ireland (Rol) to highlight the main fuel poverty metrics provide only a picture of fuel poverty and households' welfare. Labelling a particular metric 'official' risks encouraging policymakers to implement policies delivering the largest improvements in the official metric rather than policies delivering the greatest welfare improvements to the households in most need.

While gathering further evidence on the extent of fuel poverty is important, section 6.3 argues that this evidence should be seen 'in the round' and the levels of individual indicators should not be used as 'targets' against which policy performance is assessed. This recommendation goes against a conclusion of Hills (2012), when designing the UK's Low Income-High Cost (LIHC) metric, that there should be greater integration between high-level metrics and fuel poverty policies. ${ }^{11}$ Policymakers need to accept that most fuel poverty metrics are likely to be imperfect: metrics with desirable statistical characteristics may be difficult to communicate to non-specialists or require extensive, i.e. costly, data collection. Robust impact assessments

\footnotetext{
${ }^{10}$ This data (or its precursor survey) is used by Healy and Clinch (2002), Poggi and Florio (2010), Thomson and Snell (2013), Bouzarovski and Tirado Herrero (2015) and Thomson et al. (2017).

${ }^{11}$ Hills (2012), Recommendation 6, page 11 states: "The Government should use the LIHC Indicator and fuel poverty gap as the basis for operational target setting".
} 
comparing the energy expenditure (ENEX) reductions or welfare gains achieved against the costs of an intervention are a more direct way to assess the benefits of fuel poverty alleviation schemes.

The analysis for the UK, France and Rol simulates the impact of 'policy interventions' on the percentage of households devoting at least $10 \%$ of their expenditure to energy (ENEX10) ${ }^{12}$. The 'policy interventions' involve ENEX reductions or income increases targeted at alternative household groups. The simulations, presented in section 5.3, demonstrate that:

(i) even 'large' interventions reduce ENEX10 by relatively small amounts;

(ii) the 'effectiveness' of interventions in reducing ENEX10 depends on the ENEXShr distribution and average income in the target group;

(iii) and increasing household income has virtually no impact on ENEX10 despite welfare gains for households.

This analysis complements the work of Heindl and Schuessler (2015), by extending fuel poverty simulations to additional MS and highlighting the factors affecting the ability to improve recorded fuel poverty.

Given the ENEXShr variations reported in section 5.1, adopting a common ENEX based fuel poverty metric across the EU is likely to be problematic. If a common fixed ENEX threshold, such as ENEX10, were adopted, in some NMS such a high proportion of the population would be identified as fuel poor that the classification's usefulness would be lost. Equally, if a 'relative' ENEX metric was selected, the nature of households labelled as 'fuel poor' would

\footnotetext{
12 ENEX10 is analysed due to its intuitive behaviour when income and expenditure change, as noted by Heindl and Schuessler (2015). Deller and Waddams (2015b) report the results of identical simulations using the UK data for the alternative twice median ENEXShr and LIHC metrics. Deller and Waddams (2015b) highlight that these metrics may record an increase in fuel poverty following specific ENEX reductions/income increases due to movements in the position of the fuel poverty thresholds.
} 
vary considerably between MS. The large variations also suggest that a 'rational' EU-wide fuel poverty policy would require significant cross-border transfers, something which could face political obstacles. This paper's evidence provides support to the European Commission's position, expressed by Vice-President Maroš Šefčovič, that there should not be a common EU definition of energy/fuel poverty due to the differing circumstances of each MS. ${ }^{13}$

The current paper stands in contrast to Thomson et al.'s (2016) arguments that a common EU fuel poverty definition would be beneficial by increasing fuel poverty's prominence ${ }^{14}$ and clarifying the term's meaning. As any fuel poverty definition incorporates value judgements, and social policy is the responsibility of MS, it seems appropriate for democratically elected national governments to choose their preferred fuel poverty definition and policy. Also, having a common definition which is not optimised for specific MS's circumstances risks misdirecting resources. Nevertheless, the current paper agrees with Thomson et al. (2016) that the EU has a legitimate role in enabling policy synergies across MS. The EU can support synergies by increasing the availability of high-quality pan-EU affordability data, as argued by Thomson et al. (2017), and by collating robust impact assessments that identify effective policy interventions.

Section 5.2 also highlights how tracking EU-SILC indicators through time draws attention to challenges in these indicators' interpretation. The discussion of this point in section 6.2 adds

\footnotetext{
${ }^{13}$ See 'EU to tackle 'energy poverty' by Peter Teffer, EUobserver, Brussels, 30 November 2016, available at: https://euobserver.com/energy/136095 (last accessed 29.8.17). Also see: 'Maroš Šefcovic: 2016 is the year of delivery on energy union' by Rajnish Singh, The Parliament Magazine, Brussels, available at: https://www.theparliamentmagazine.eu/articles/interviews/maro\%C5\%A1-\%C5\%A1efcovic-2016-yeardelivery-energy-union (last accessed 29.8.17).

${ }^{14}$ Bouzarovski et al. (2012) argue the lack of an institutional centre has made fuel poverty's position within European institutions precarious.
} 
to Thomson et al. (2017) and Tirado Herrero (2017) by specifying lived experience indicators which capture tightly defined situations faced by fuel poor households.

\section{Background - Energy Affordability Indicators}

There are a variety of ways to assess energy affordability and fuel poverty, as discussed by Thomson et al. (2017) and Tirado Herrero (2017). Figure 1 shows how these indicators broadly fall into three categories: (a) ENEX-based indicators, (b) self-reports of the lived experience ${ }^{15}$, and (c) proxy indicators. As argued by Tirado Herrero (2017), it is difficult to identify a single 'best' affordability metric, with different indicators providing different pieces of evidence. The long-term task must be to triangulate the varying evidence to obtain a richer understanding of energy affordability and/or fuel poverty. The purpose of the present paper is to illustrate issues and questions surrounding the existing indicators of types (a) and (b). A detailed discussion of these issues and potential ways forward for policymakers is provided in section 6.

When attempting to assess energy affordability across the EU, proxy indicators appear less desirable than indicators (a) and (b) since they are 'indirect': their validity is dependent on robust statistical relationships existing with indicators (a) and (b). These statistical relationships could vary between MS and through time, and establishing these relationships is beyond the scope of this paper. While proxy indicators are not used in Sections 5.1 and 5.2, they may be attractive for policy targeting as data on their prevalence may already be collected by government. For this reason, proxy indicators are used to 'target' policies in Section 5.3.

\footnotetext{
${ }^{15}$ Indicators of type (b) are referred to as 'Consensual' by Thomson et al. (2017) and Tirrado Herrero.
} 


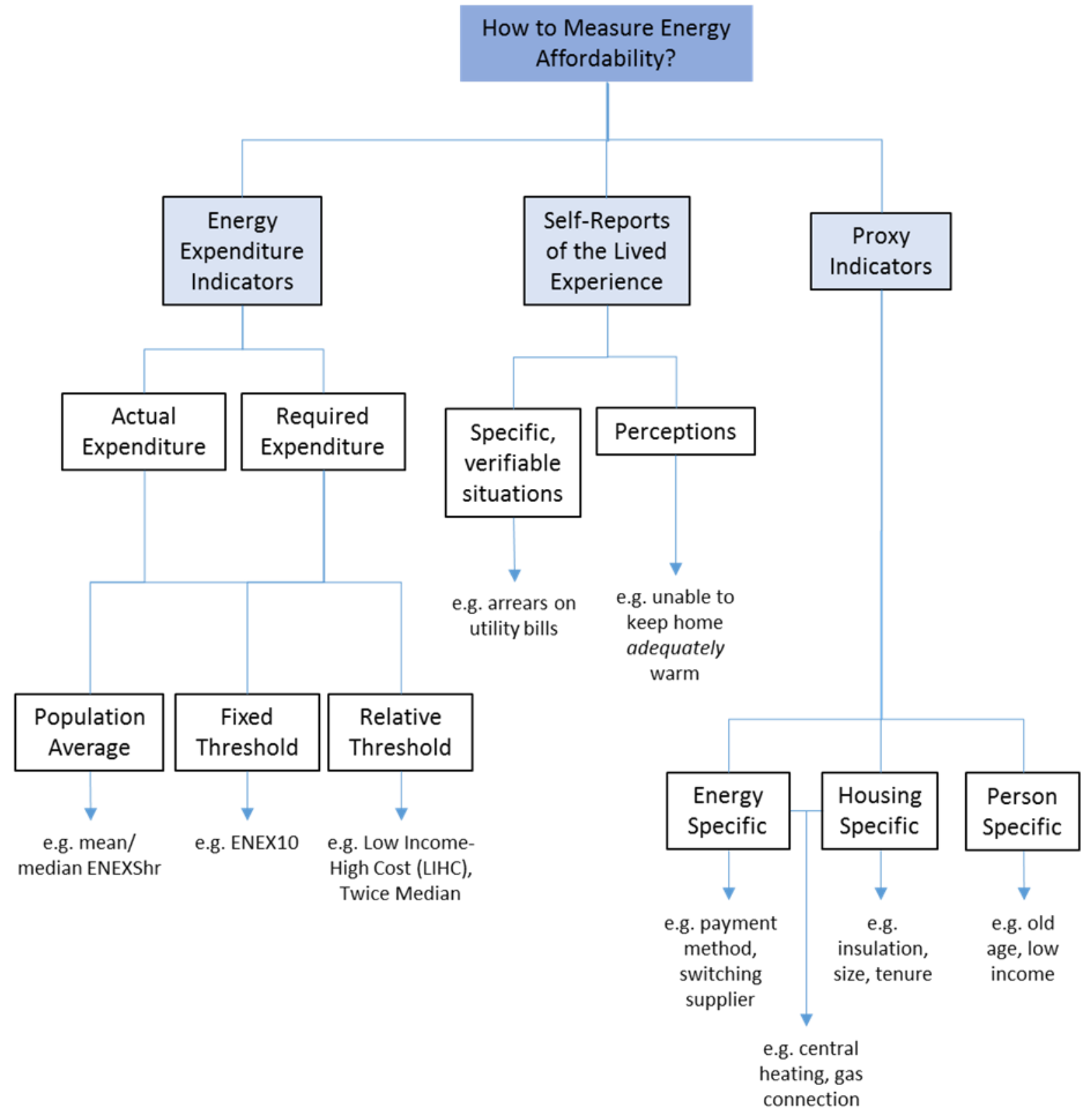

Figure 1: Alternative indicators of energy affordability

Beyond proxy indicators, a major set of indicators not studied in this paper are those based on required ENEX, since only actual ENEX figures are available at the pan-EU level. Required ENEX is where the ENEX for a household to achieve a particular target temperature (and other specified energy services) is modelled on the basis of a dwelling's physical characteristics. Required ENEX has the intuitive attraction over actual ENEX that it is not depressed if a household consciously restricts energy consumption due to affordability difficulties. 
However, as Tirrado Herrero (2017) notes, required ENEX is dependent on the quality of the assumptions and modelling employed to calculate it, hence, the advantage of required ENEX over actual ENEX is less clear than it first appears.

Two further points are worth noting. First, while population averages are useful indicators to assess energy affordability, they are less useful in identifying the fuel poor. Second, splitting self-reports of the lived experience into two distinct categories is deliberate: although householders' perceptions provide information about their view of a situation, respondents may attach different meanings to phrases such as "adequate" and "keep warm". ${ }^{16}$

\section{Methodology}

Two main methods are followed: (i) analysis of descriptive statistics utilising high-level data from Eurostat data tables, and (ii) simulations of alternative policies on ENEX-based fuel poverty rates harnessing micro-data from France, the ROI and the UK.

\subsection{Calculating EU Averages}

In section 5.1 the average ENEXShr reported for the EU15, EU28 and NMS are weighted means: each MS's contribution is weighted by a MS's percentage of the total 2013 population of the MS used to calculate the relevant average. ${ }^{17}$ This means large MS, such as Germany, have more influence on the averages than small MS, such as Luxembourg. The weighted averages use the subset of MS where Eurostat provides ENEXShr data for all years. ${ }^{18}$ This approach avoids intertemporal fluctuations resulting from changes in the set of MS

\footnotetext{
${ }^{16}$ See Tirrado Herrero (2017) for further discussion.

${ }^{17}$ Eurostat's ENEXShr averages are not used as they do not always cover all time periods or the sub-group of MS considered. The population figures are available at: http://appsso.eurostat.ec.europa.eu/nui/show.do?dataset=demo pjan\&lang=en (last accessed 29.8.17).

${ }_{18}$ The MS contributing to the averages in particular figures are described in section 4.1.
} 
considered. These weighting methods are also used when calculating the averages of the EUSILC indicators in section 5.2.

As the EU averages are based on Eurostat's data tables rather than micro-data from individual MS, the averages are intended to be illustrative and to spur further research.

\subsection{Policy Simulations}

Although Eurostat's aggregate ENEXShr data provides an overview of energy affordability in the EU, a greater understanding requires micro-data from individual households. Household level data makes it possible to: (a) compare the fuel poverty rate when using alternative fuel poverty metrics and (b) assess the impact of policies on the fuel poverty rate.

The simulations complement work by Heindl and Schuessler (2015). Compared to Heindl and Schuessler, not only are additional MS considered, but the current simulations are more applied, investigating how targeting policies at alternative household groups influences ENEX10. In contrast, Heindl and Schuessler use ENEX and income changes to explore the behaviour of alternative fuel poverty metrics. By considering ENEX10 in MS beyond Germany and a wider range of target groups, the simulations also complement Heindl (2013). ${ }^{19}$

In Section 5 the policy simulations investigate the impact of four interventions:

(a) €250 increase in income (proxied by increasing total expenditure)

(b) €50 decrease in ENEX

(c) $€ 100$ decrease in ENEX

\footnotetext{
${ }^{19}$ Looking at ENEXShr in a European perspective also extends Advani et al. (2013) beyond the UK.
} 
(d) $€ 250$ decrease in ENEX 20

These figures were chosen as plausible amounts given the value of energy bills and the likely cost of the interventions. For the years considered, $€ 250$ represents, as a percentage of median household energy expenditure, $18.7 \%$ in the UK, $22.7 \%$ in France and $15.5 \%$ in the Rol. Table A2 shows the inteventions' indicative costs would be substantial; monetary transfers of $€ 250$ to the largest target groups in France and the UK would cost around $€ 2 \mathrm{bn}$ per annum per intervention in 2017 prices $^{21}$. The simulations represent additional interventions over and above any fuel poverty schemes in place when the surveys took place. The particular policies that achieve (a)-(d) (e.g. improved insulation vs monetary transfers) are not assessed, rather the effect of (a)-(d) on ENEX10 is evaluated. It is assumed that the ENEX reductions do not reduce households' welfare, simply the cost of energy services. Interventions (a)-(d) are targeted at different sections of the population, e.g. single parent households vs retired households, with the target groups chosen according to the availability of identifiers within each survey.

The simulations do not incorporate households' response to increases in income/decrease in ENEX. In reality, households will likely adjust their consumption of all goods in response to an intervention. Modelling these demand responses is beyond the scope of the paper. In particular, a $€ 250$ income increase may stimulate an increase in ENEX. Depending on the size of the ENEX increase, an income increase could even lead to an individual household's

\footnotetext{
${ }^{20}$ For the UK, conversion into pounds sterling used the market exchange rate on 29 June 2012 of 0.8068 euros to the pound.

${ }^{21}$ Costs for the UK were converted into Quarter 22017 prices using the ONS's Consumer Price Index (CPI), see https://www.ons.gov.uk/economy/inflationandpriceindices/timeseries/d7bt/mm23 (last accessed 8/12/17). Cost for France and the Rol utilised the ECB's Harmonised Index of Consumer Price (HICP), see http://www.ecb.europa.eu/stats/ecb statistics/escb/html/table.en.html?id=JDF ICP COICOP INX\&period=20 17-06 (last accessed 8/12/17).
} 
ENEXShr increasing. ${ }^{22}$ While ignoring demand response is a significant simplification, including it is likely to reinforce the paper's findings that: (a) even 'large' interventions reduce ENEX10 by small amounts and (b) increasing income has a particularly small impact on ENEX10.

The first step in the simulations was to estimate ENEX10 for the population as a whole. Interventions (a)-(d) were then applied to the different target groups. ${ }^{23}$ Since ENEX is a component of total expenditure, total expenditure was also recalculated after interventions (b)-(d). ${ }^{24}$ Lastly, ENEX10 for the population as a whole was recalculated after each intervention.

As explained in section 5.3.2, a range of factors determine an intervention's ability to move the central estimate of ENEX10. To summarise the impact of these factors an 'effectiveness' metric has been constructed which can be interpreted (assuming the ENEX reductions are monetary interventions $)^{25}$ as the percentage point change in ENEX10 per $€ 100 \mathrm{~m}$ of policy expenditure per annum. The metric is calculated by dividing the percentage point change in ENEX10 resulting from an intervention by the number of households in the target group ${ }^{26}$ and the value of the monetary intervention before multiplying the resulting figure by $100 \mathrm{~m}$. This metric aids comparison between interventions within a given MS, however, caution is needed

\footnotetext{
${ }^{22}$ A simple numerical example illustrates this point. Consider a household with an initial income of $€ 10,000$ and an ENEX of $€ 1,000$ which receives an income supplement of $€ 250$ and chooses to spend $€ 50$ of this on ENEX; here ENEXShr will rise from $10 \%$ to $10.2 \%$. However, generally energy is an income inelastic product, i.e. for a given percentage increase in income ENEX will increase by a smaller percentage amount, hence, households that see ENEXShr increase following an income increase are likely to be rare.

${ }^{23}$ If an intervention resulted in negative ENEX, ENEX was put to zero in France and the Rol. This was not done for the UK as the raw data treated negative ENEX as legitimate due to rebates associated with the UK's energy billing system.

${ }^{24}$ Without this adjustment, interventions (b)-(d) would have a slightly greater impact on reducing ENEX10.

${ }^{25}$ In theory, energy efficiency investments or education programmes might reduce ENEX by $€ 100 m$ for less than $€ 100 m$ of policy expenditure.

${ }^{26}$ Household numbers were obtained by multiplying the percentage of households in a target group identified from the survey data with the total number of households in the relevant MS obtained from the UNECE Statistical Database, see at: http://w3.unece.org/PXWeb2015/pxweb/en/STAT/STAT 30-GE 02Families households/08 en GEFHPrivHouse r.px/?rxid=639ea214-8b4c-4e78-80dc-35f243ef0be4 (last accessed 7/12/17). The household population figures for France and the Rol refer to 2010.
} 
before comparison across MS as the more households there are within a MS the greater the cost of moving ENEX10. Given the multiple sources of uncertainty present, the 'effectiveness' metric is purely indicative of the difficulty of moving ENEX10 across interventions rather than a robust cost estimate.

Effectiveness is placed in inverted commas as the metric illustrates how interventions alter the picture of ENEX10 fuel poverty rather than households' actual welfare. Assuming the interventions are monetary transfers, the intervention with the highest effectiveness value will result in the greatest percentage point change in the central estimate of ENEX10 for a given cost, although, the magnitude of the resulting change in ENEX10 could be (very) small. For both the ENEX10 and 'effectiveness' metric results, two benchmarks are included to aid interpretation: (i) applying each monetary intervention to all households and (ii) applying each intervention to households with ENEXShr in the top decile.

\section{Data}

\subsection{Eurostat Data}

A pan-EU perspective on energy affordability is possible using two data sources: (i) Eurostat's collated household budget survey database ${ }^{27}$ and (ii) EU-SILC data ${ }^{28}$. (i) enables comparison of average ENEXShr, while (ii) includes the percentage reporting an 'inability to keep your home adequately warm' and the percentage reporting 'arrears on utility bills'. ${ }^{29}$ The existing literature (see footnote 10) focuses on the EU-SILC data as it provides annual indicators which

\footnotetext{
${ }^{27}$ See: http://ec.europa.eu/eurostat/web/household-budget-surveys/database (last accessed 29.8.17).

${ }^{28} \mathrm{See}$ http://ec.europa.eu/eurostat/web/income-and-living-conditions/data/database (last accessed 30.11.17)

${ }^{29}$ The percentage of households with leaks, damp or rot has been used in the past as an additional proxy for fuel poverty. This indicator is not used here as the strength of its link to energy affordability pressures is not entirely clear: damp and rot can result from ventilation issues rather than a lack of heat.
} 
fit intuitive concepts of fuel poverty. For both (i) and (ii) the present analysis is based on Eurostat's high-level database rather than the micro-data of the underlying surveys.

As well as the Eurostat ENEXShr data having less to say on fuel poverty directly, it is only available at roughly 5 year intervals from 1988 to 2010. Nevertheless, average ENEXShr have clear value in understanding general energy affordability and, in particular, the political economy of energy markets. For example, the increasing emphasis on fuel poverty might represent a political response to a decline in affordability for average households, as much as increased concern for the fuel poor.

The ENEXShr calculation is based on the structure of the mean consumption expenditure of private households in each MS and involves the numerator 'Electricity, gas and other fuels' (COICOP level CP045) and the denominator is all household consumption expenditure (COICOP level CP00). As noted above, only for a subset of MS are data available in all time periods. The EU15 average in Figure 2 is based on $8 \mathrm{MS}^{30}$, while the EU28 average in 2005 and 2010 is based on all MS bar Italy. In Figure 2, data on NMS covers all relevant MS, but is available only in 2005 and 2010. In Figure 4, MS are included that have data available for all years for all subgroups, however, to retain a reasonable number of EU15 MS the time series in Panel A only covers 1994 to 2010. Figure 4 Panel A draws on data for 9 EU15 MS ${ }^{31}$ and Panel B draws on data for $10 \mathrm{NMS}^{32}$.

Two further points regarding the Eurostat ENEXShr data should be recognised. First, the observed variations between MS may reflect variations in definitions, survey timing and survey methodologies. In particular, the UK, Czech Republic and Hungary do not include

\footnotetext{
${ }^{30}$ Belgium, Greece, Spain, France, Luxembourg, the Netherlands, Portugal and the UK.

${ }^{31}$ Belgium, the Rol, Greece, Spain, France, Austria, Portugal, Finland and the UK.

32 The NMS excluded are: the Czech Republic, Romania and Slovenia.
} 
imputed rent for owner-occupiers in total expenditure. This increases the (apparent) ENEXShr of these MS compared to other MS. Second, only central estimates are reported in the Eurostat data tables used to produce Figures 2 to 5. However, Eurostat (2015) ${ }^{33}$ reports 95\% confidence intervals for the share of household expenditure devoted to the larger COICOP level CP04 'Housing, water, electricity, gas and other fuels' in the 2010 wave. In all MS apart from Portugal ${ }^{34}$ the confidence interval resulting from sampling error is reported as less than \pm 0.1 percentage point. ${ }^{35}$ This suggests the differences reported in Figures 2 to 5 are likely to be statistically significant.

Turning to the EU-SILC data, Figures 6 and 7 cover the period 2005 to 2016 . Due to incomplete time series over this period the UK and Rol are dropped from the EU15 averages, while Romania and Croatia are dropped from the NMS averages.

\subsection{National Level Micro-Data}

In the absence of harmonised EU-wide ENEX micro-data, policy simulations are performed on micro-data from France, the Rol and the UK. ${ }^{36}$ The datasets used in the simulations are: the Living Costs and Food Survey $2012^{37}$ for the UK, the Enquête Budget de Famille 2010-11 for France and the Irish Household Budget Survey 2009-10.

\footnotetext{
${ }^{33}$ See Table 5, page 12.

${ }^{34}$ The confidence interval for Portugal is reported as \pm 0.7 percentage points.

${ }^{35}$ Equivalent high-level information for the EU-SILC indicators used in this paper does not appear available in the relevant Eurostat quality reports.

${ }^{36}$ The UK and Rol were chosen due to the free availability of their household budget surveys and English documentation. France was selected due to the interests of a CERRE project sponsor. Additional detail on the simulations is available in Deller and Waddams (2015b), Deller and Waddams (2015c) and Deller and Waddams (2015d).

${ }^{37}$ The simulations do not apply corrections for seasonality and the data is also left unequivalised. Deller and Waddams (2017) highlight that in the UK's Living Costs and Food Survey prior to 2013 a significant proportion of households using a Pre-Payment Meter (PPM) to pay for energy report zero ENEX and this is likely to be a case of missing/misreported data. PPMs are disproportionately located in low income households due to their use to manage energy debts. Correcting this data issue would increase reported ENEX10 in the UK, particularly for households with total expenditure beneath $60 \%$ of the median, an unemployed household head and/or living in social housing. The impact of a correction on the simulation results is harder to assess.
} 
For each MS the denominator in ENEXShr is the total annual household expenditure variable ${ }^{38}$ included in the dataset which is inclusive of recorded housing costs. ${ }^{39}$ In the UK, ENEX includes expenditure on gas, electricity and other fuels ${ }^{40}$ used to provide energy in the home as well as ENEX in second dwellings. In France, ENEX only includes expenditures on mains gas and electricity $^{41}$. In Rol, ENEX represents expenditure on electricity, gas, liquid fuels and solid fuels.

As the surveys occur in different years and have different methodologies, each MS is treated as a 'case study'. In each MS the weights provided with the survey data are utilised to ensure the data is representative of the population as a whole. There are two specific differences between the datasets and households worth highlighting. First, as with the Eurostat data, total expenditure in the UK excludes imputed rent for owner-occupiers. Second, the Enquête Budget de Famille includes some of France's overseas territories, however, the weighting ensures this dataset is representative of France and its overseas territories combined. Since the population of mainland France far exceeds that of the included overseas territories, the results should be driven by mainland France. Appendix A describes differences in household characteristics between MS.

\section{Results and Discussion}

Results from three distinct, but linked, pieces of analysis are reported. In section 5.1 the Eurostat ENEXShr data is used to argue that an ENEX-based fuel poverty indicator is unlikely

\footnotetext{
${ }^{38}$ In France the base variable used was 'ctot', in the UK it was 'P550tp', and Rol it was 'he620'.

${ }^{39}$ Total expenditure rather than income was used due to the relative simplicity of its definition. Furthermore, it can be argued that total expenditure provides a better indication of living standards, for example, see Brewer and O'Dea (2012).

40 This includes expenditure on bottled gas, paraffin, coal/coke, wood/peat and hot water/steam/ice.

${ }^{41}$ The analysis was restricted to these two significant categories of ENEX due to the complexity of the variables recording ENEX on other fuels.
} 
to be suited to the specific purpose of providing a single pan-EU fuel poverty indicator. The simulations reported in section 5.3 widen the critique of ENEX-based fuel poverty indicators to the general policymaking setting by emphasising these indicators only ever provide a 'picture' of fuel poverty. Unless used with sophistication, there is the risk that targeting policy based on these indicators distorts policy towards managing the statistical 'picture' of fuel poverty rather than maximising improvements to the lived experience of households on the ground.

In response to this critique one may wonder whether self-reports of the lived experience offer a solution to the challenges of fuel poverty measurement. The results in section 5.2 highlight that self-reports potentially have their own issues as indicators. While not offering definitive conclusions, section 5.2 is intended to motivate further detailed research into understanding the behaviour of self-reports before they become hard-wired into policymaking.

Responding to these pieces of evidence, section 6 provides guidance on how policymakers may proceed while addressing the critiques raised in this paper.

\subsection{Mapping Energy Expenditure Shares across the EU}

\subsubsection{Differences in Average Energy Expenditure Shares}

The main finding, shown in Figure 2, is that, on average, households in NMS devoted a substantially higher proportion of their expenditure to energy than households in the EU15 (10.9\% vs $4.6 \%$ in 2010$)$. The higher ENEXShr in NMS probably reflect significantly lower average incomes and, probably, lower quality housing. It is also noticeable that the EU15's average ENEXShr is stable through time at around $4 \%$. 


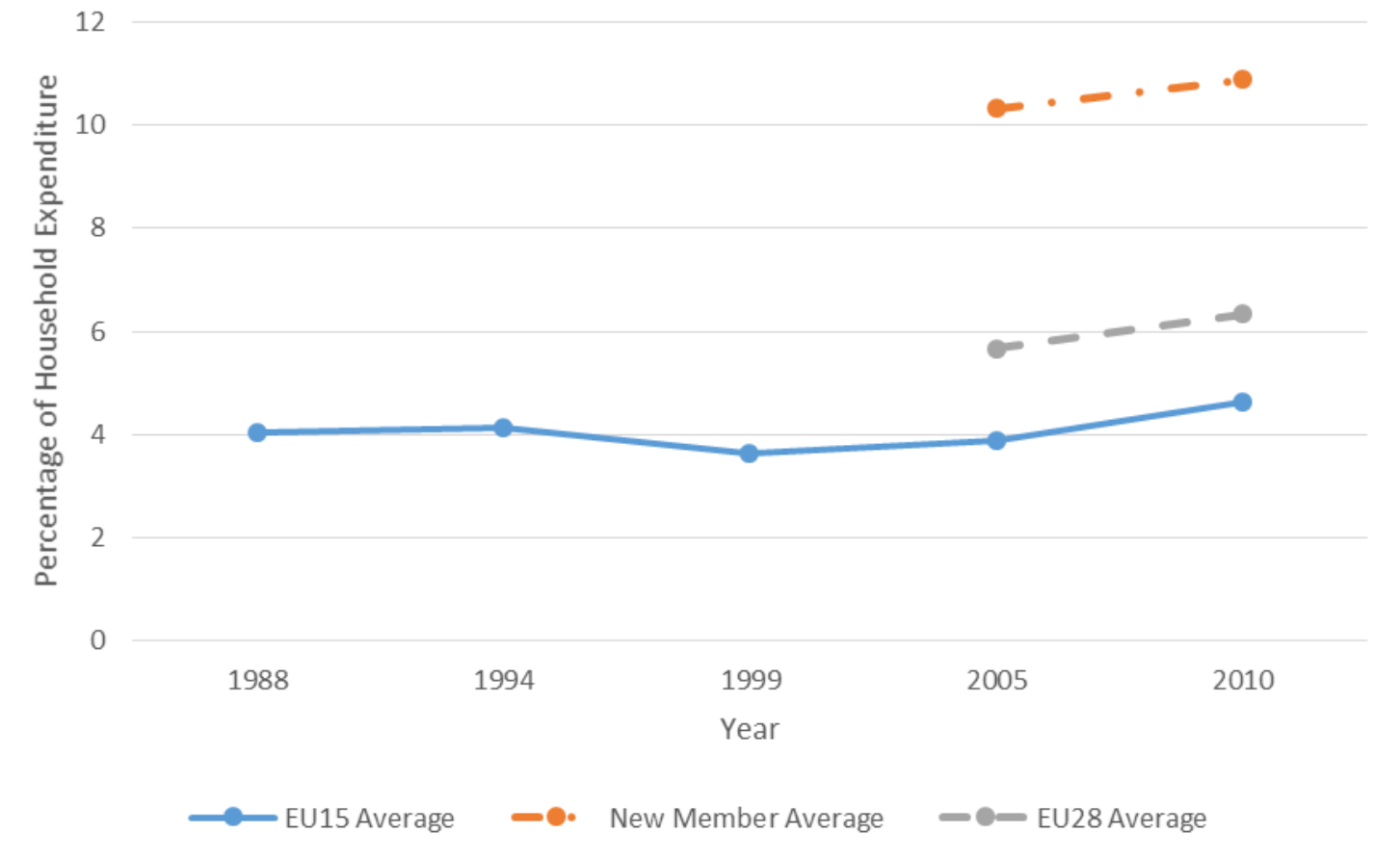

Figure 2: Average energy expenditure shares in the EU15, NMS and EU28

Figure 3 shows that differences between individual MS can be starker, for example, the average ENEXShr in Malta in 2010 was $2.7 \%$ compared to $16.5 \%$ in Hungary. There are also notable variations in the evolution of ENEXShr through time; while Hungarian and Romanian households both had an ENEXShr around 11.5\% in 2005, by 2010 the average in Hungary had increased by 4.9 percentage points but had fallen by 2.2 percentage points in Romania. 

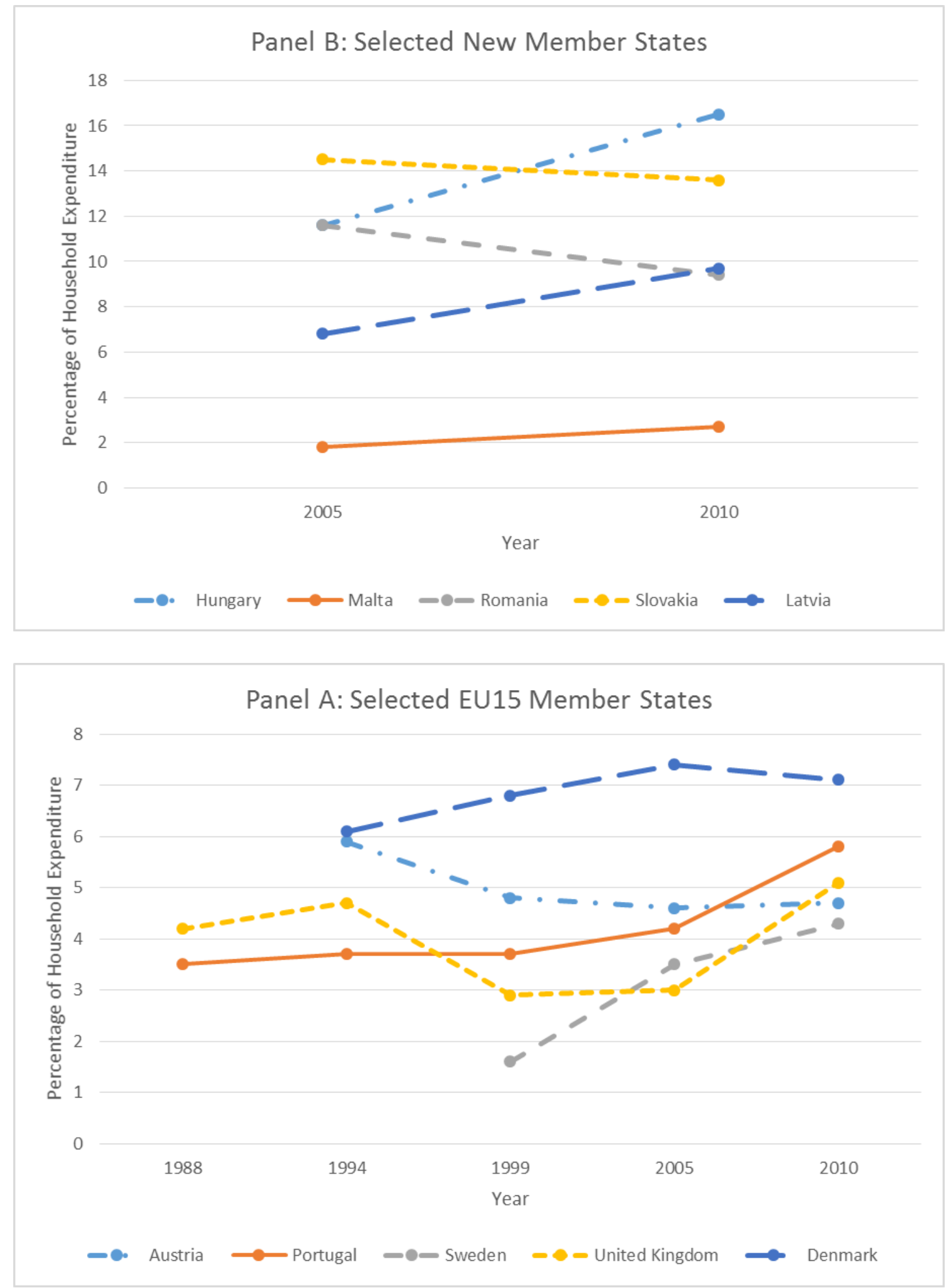

Figure 3: Average energy expenditure shares in selected EU15 Member States (Panel A) and New Member States (Panel B) 
The large differences between MS indicate that a common EU fuel poverty definition based on ENEX would be problematic: a metric/threshold identifying severe fuel poverty in one MS (e.g. Malta) would cover a large section of the population in another MS (e.g. Hungary). That Hungary's average ENEXShr was 16.5\% in 2010 implies the majority of Hungarian households would have been classified as fuel poor according to ENEX10. ${ }^{42}$ In Hungary the value of an ENEX10-based 'fuel poor' designation to target resources would be seriously weakened. Also, if a common metric supported an EU-wide fuel poverty policy, a 'rational' strategy would involve resource transfers from MS with the lowest fuel poverty rates to those with the highest. Realising such a strategy could be challenging as national governments, quite reasonably, may make different judgements regarding acceptable energy inequalities.

Perhaps recognising that identifying a large percentage of households as fuel poor is unhelpful, EC (2010) suggested twice the national average ENEXShr as an appropriate metric to identify a 'considerable (energy) expenditure share'. While such a metric allows a common and relevant fuel poverty definition across MS, the households identified as fuel poor in each MS will face very different circumstances. Taking examples from Figure 3, a fuel poor household in Sweden would have had an ENEXShr of at least $9 \%$ in 2010, while a fuel poor household in Hungary would have had an ENEXShr of at least $32 \%$. Relative metrics, i.e. those linked to the 'average' situation in individual MS, enable a comparison of ENEXShr inequality between $\mathrm{MS}^{43}$, but cannot provide straightforward comparisons regarding the depth of fuel poverty. For fixed threshold ENEX metrics, such as ENEX10, the issues are reversed:

\footnotetext{
42 The Czech Republic, Poland and Slovakia also had average ENEXShr exceeding 10\% in 2010.

${ }^{43} \mathrm{~A}$ greater proportion of households reporting ENEX above 'twice the national average' indicates greater inequality.
} 
comparisons of fuel poverty levels between MS are straightforward but a common metric cannot effectively target policies in all MS.

\subsubsection{Inequalities in Energy Expenditure Shares}

While not addressing fuel poverty directly, the ENEXShr data allows evaluation of more general distributional issues by breaking out ENEXShr by household type. Figure 4 shows the ordering of average ENEXShr across household types is the same for the EU15 and NMS: retired households and households in the bottom income quintile have the highest ENEXShr, while households with children have the lowest.

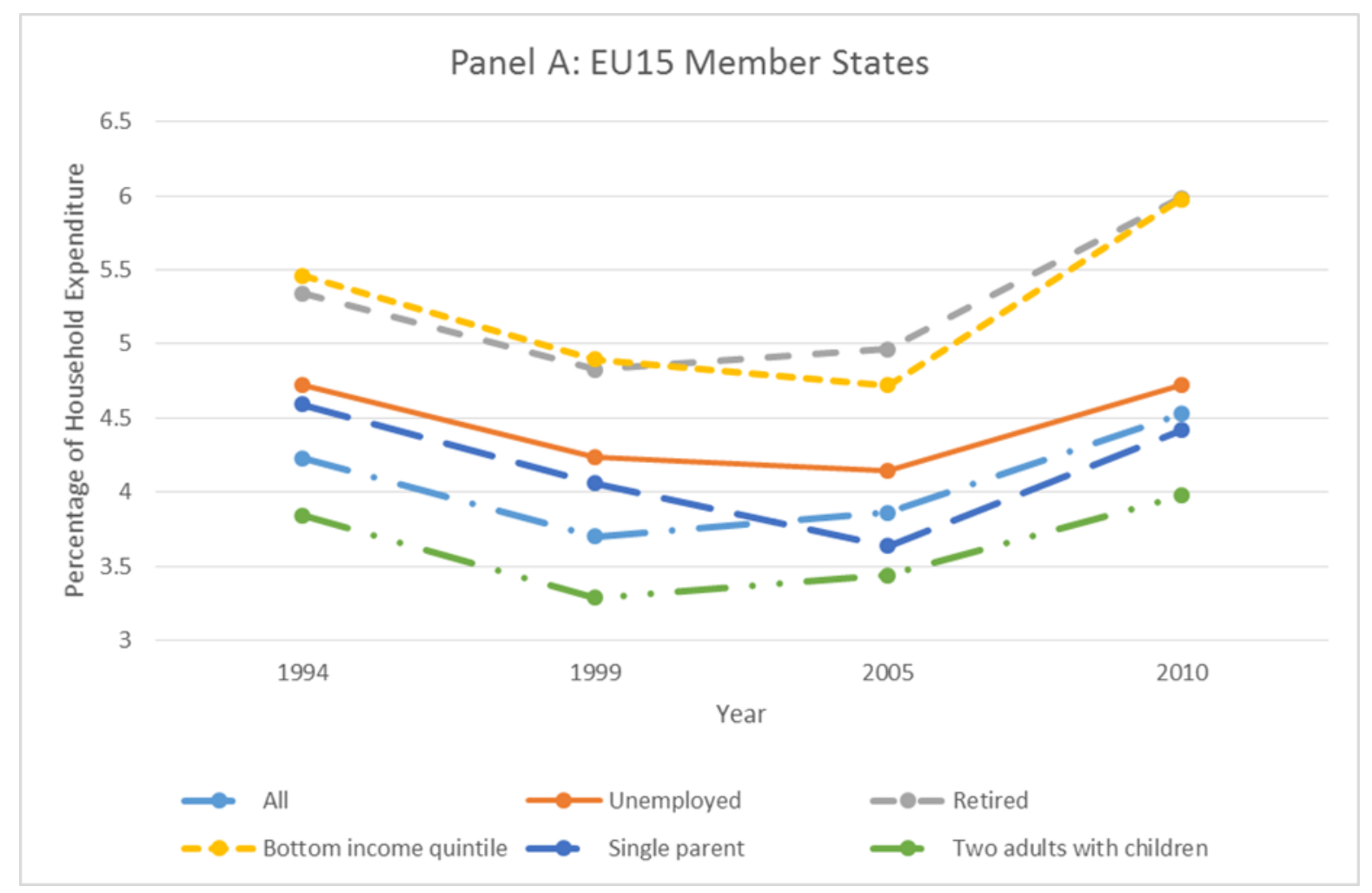




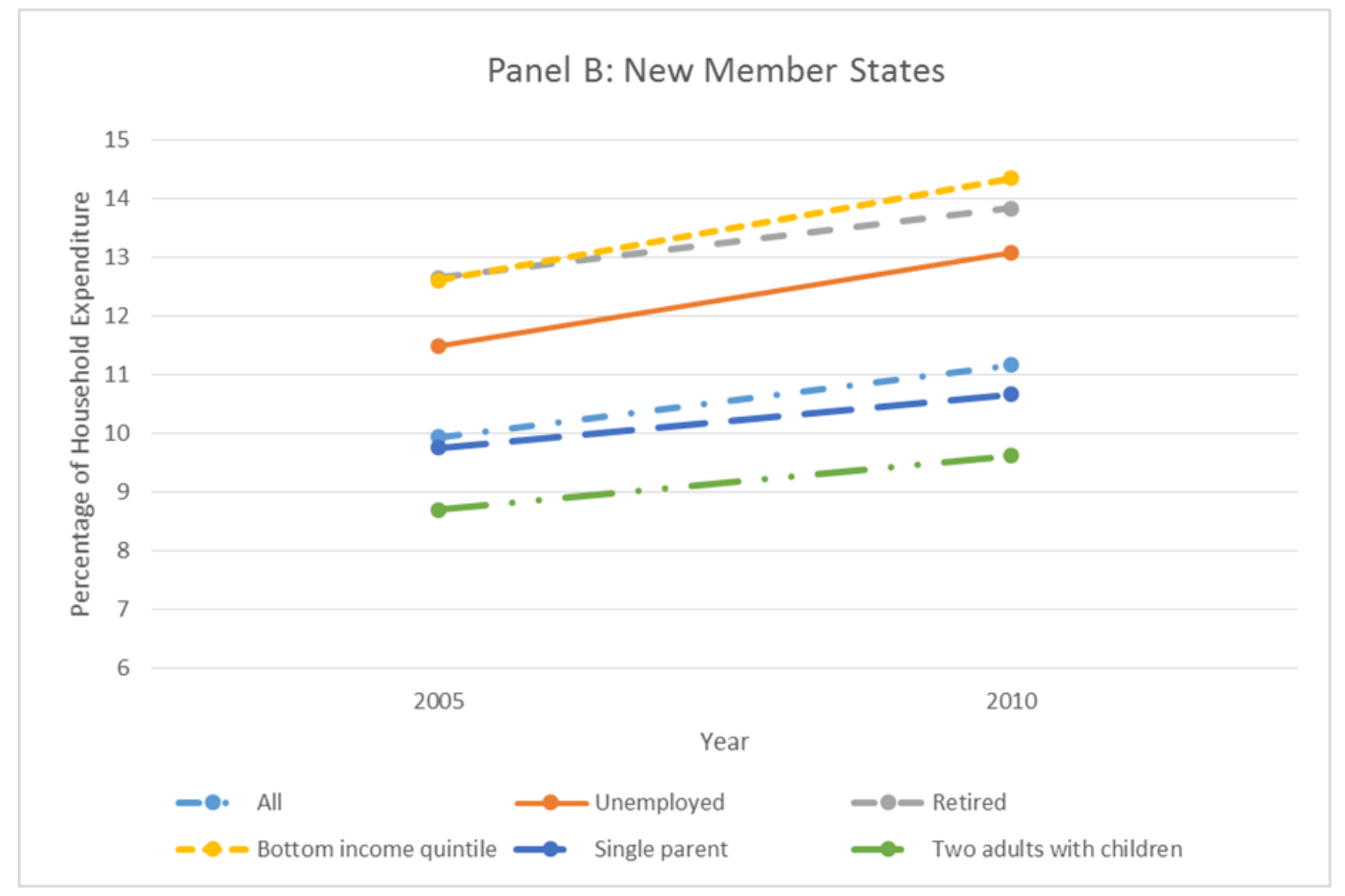

Figure 4: Energy expenditure shares by household type averaged across the EU15 (Panel A) and NMS (Panel B)

The 'equality' of energy outcomes can also be assessed using the ratio of the average ENEXShr for households in the bottom income quintile relative to the average ENEXShr for all households. This ratio is reported for selected MS in Figure 5. A higher value indicates greater inequality, however, it does not automatically imply a 'problem' with the energy market: a higher value could result from greater income inequality. 

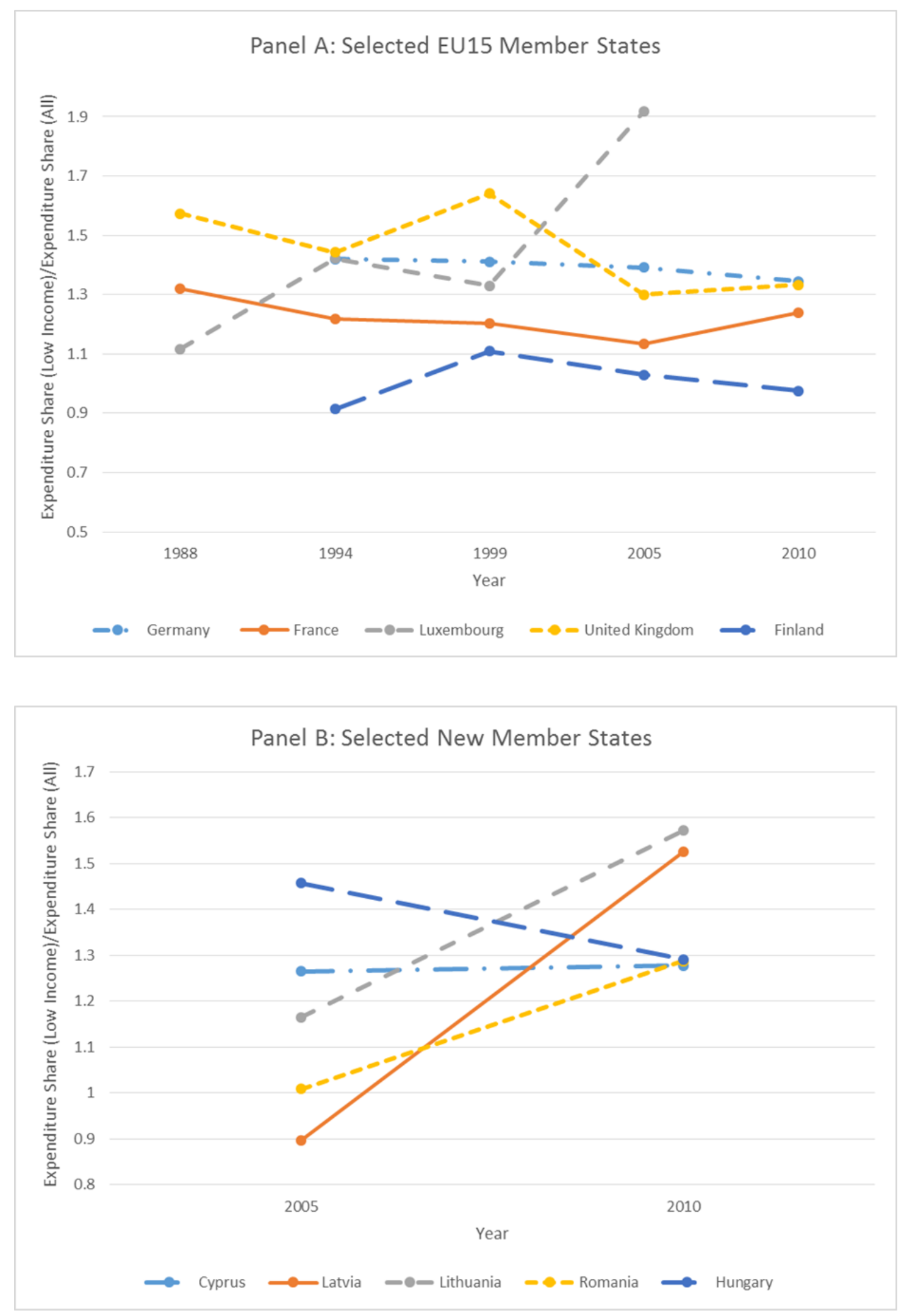

Figure 5: The average energy expenditure share for low income households as a multiple of the average energy expenditure share for all households - selected EU15 Member States (Panel A) and selected New Member States (Panel B) 
The average ENEXShr for households in the bottom income quintile is generally $20-50 \%$ higher than the average ENEXShr for all households. However, within the EU15, Finland, Sweden and Austria have ENEXShr that appear more 'equitable': in 1994 the poorest households in Finland and Austria had a lower ENEXShr than the average household.

In NMS the gap between the low income and all household average generally widened between 2005 and 2010; it fell in only three NMS: Hungary, Malta and Poland. This widening might reflect increased market liberalisation or the removal of energy subsidies which could have led to prices rising faster than incomes for the poorest households. Figure 5 shows this widening was particularly severe in Latvia. In 2005 the average ENEXShr of low income households in Latvia was $10 \%$ below the all household average, however, by 2010 low income households had an ENEXShr that was 53\% above the all household average.

\subsection{Intertemporal Variations in EU-SILC Indicators}

While EU-SILC indicators' annual collection is a key advantage over the Eurostat ENEXShr data, the EU-SILC indicators must be critically assessed before they are hard-wired into policymaking. The two EU-SILC indicators considered here are: (a) the percentage reporting an 'inability to keep your home adequately warm' and (b) the percentage reporting 'arrears on utility bills'. Once these indicators are considered intertemporally new issues and avenues for research emerge.

Key papers investigating fuel poverty across the EU using EU-SILC/European Community Household Panel (ECHP) indicators are Healy and Clinch (2002) and Thomson and Snell (2013), however, their consideration of intertemporal variations is limited. Thomson and Snell (2013) focus on the cross-sectional variation in fuel poverty between MS using data from 2007, while 
Healy and Clinch's (2002) consideration of intertemporal changes is limited to $1994-97 .{ }^{44}$ Each set of authors also aggregate individual indicators into indices, however, aggregation does not automatically address concerns about the information which the individual indicators convey. Indeed, aggregation can lead to the information from individual indicators being obscured.

The most sophisticated intertemporal analysis using EU-SILC/ECHP data is Poggi and Florio (2010). Poggi and Florio use data for a subset of MS from 1994-2001 and 2004-05 to investigate the potential association between privatisation, liberalisation and vertical disintegration and the level of "Energy deprivation", as measured by indicator (b) ${ }^{45}$, using panel data methods. While using indicator (b) as a proxy for energy deprivation may be reasonable given the data available, the present discussion of whether better indicators can be identified has clear value.

The first example of issues with the EU-SILC indicators results from comparing the average values of (a) and (b) for the EU15 and NMS in Figure 6. While both indicators (a) and (b) show a clear improvement between 2005 and 2016 for NMS, the decline for indicator (a) is noticeably larger than for indicator (b). Moreover, Figure 6 shows a conflicting intertemporal variation for (a) and (b) within NMS between 2008 and 2014. Between 2008 and 2014 the average percentage reporting an inability to keep their home warm in NMS fell by 8.6 percentage points, while the average percentage reporting utility arrears rose by 4.1 percentage points. Looking at these indicators individually over this period would lead to

\footnotetext{
${ }^{44}$ Figure 3 of Thomson et al. (2017) reports indicators (a) and (b) from 2005 to 2014, although, only the EU27 average.

${ }^{45}$ In the ECHP the question was phrased as the inability to pay scheduled utility bills as opposed to arrears.
} 
opposite conclusions as to whether energy affordability difficulties were: (i) worsening or improving in NMS and (ii) converging or diverging between the EU15 and NMS.

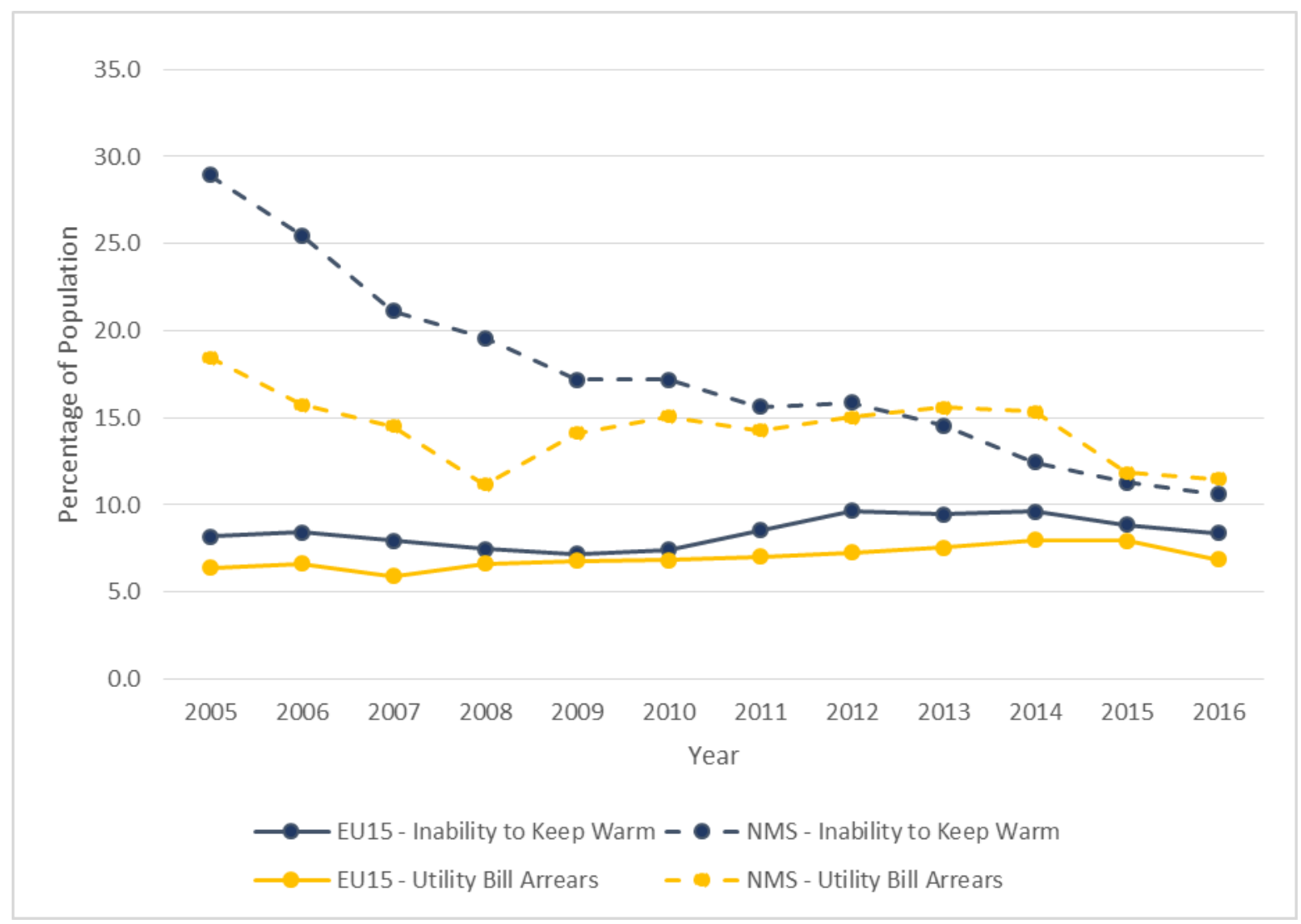

Figure 6: Percentage of the population reporting an inability to keep their home warm compared to the percentage reporting utility bill arrears in the EU15 and NMS

The second example is to consider indicator (b) broken down by household type; Figure 7 reports the varying arrears rates in the EU15. Those living in households containing a person over the age of 65 are least likely to report arrears in the EU15. In NMS a similar ordering of household groups by arrears rates exists, although, for brevity, this is not reported graphically. ${ }^{46}$ However, there are at least four possible explanations for this observation: (i) older households are wealthier; (ii) policies subsidise utility consumption by the elderly more than other groups; (iii) older households are more conscientious bill payers; and (iv) older

\footnotetext{
${ }^{46}$ The absolute level of utility bill arrears in NMS is 1.5 to 3 times the level in the EU15.
} 
households feel a greater social stigma when admitting arrears. While (i) and (ii) involve the fundamentals of fuel poverty, one might be concerned that (iii) and (iv) represent other issues. Understanding the factors driving utility arrears becomes more important when one recalls that older households have some of the highest ENEXShr.

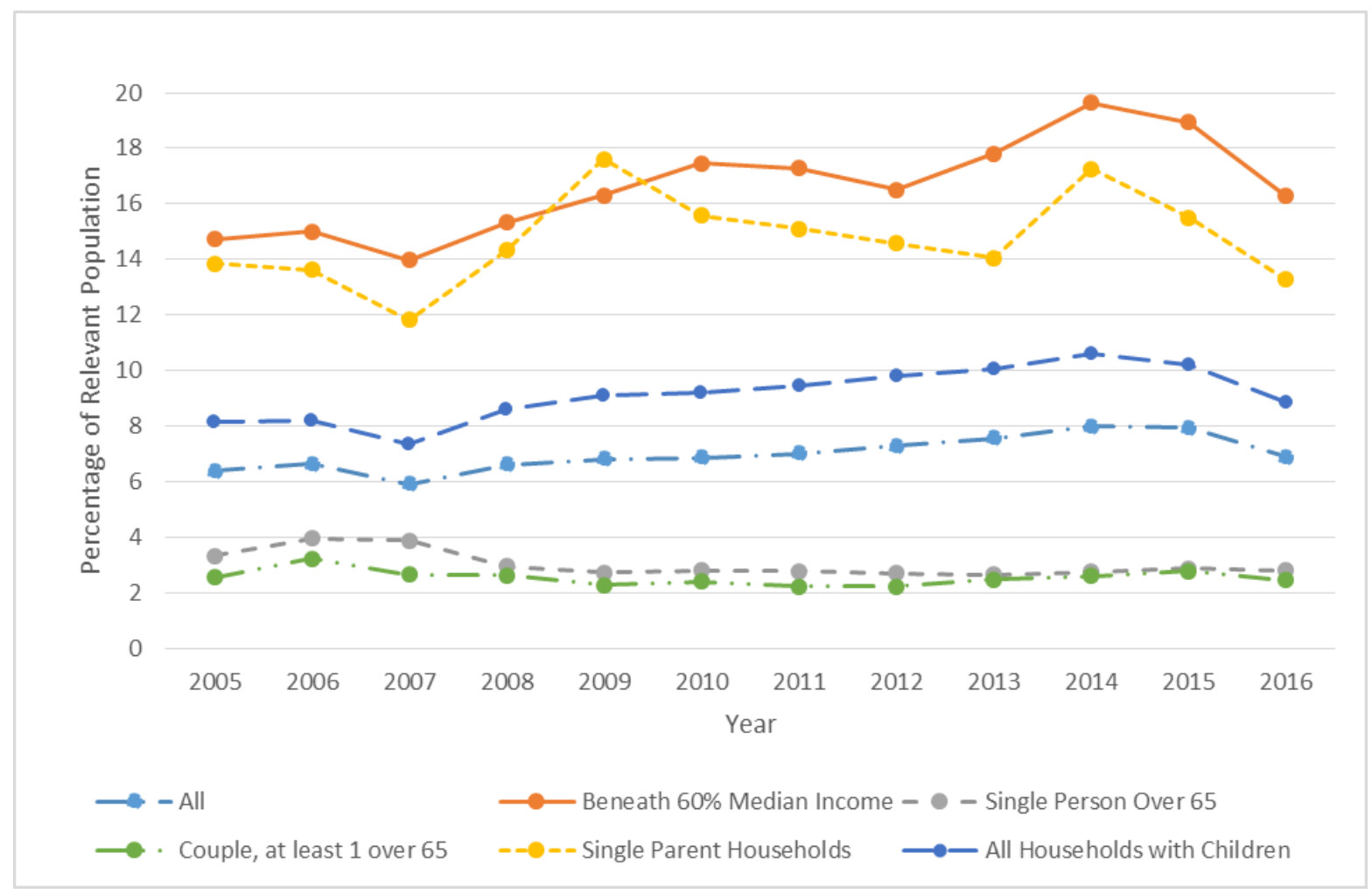

Figure 7: Average percentage of relevant population reporting utility arrears in the EU15 by household type

\subsection{Policy Simulations}

For brevity, the simulation results for France and Rol are reported in Appendix B. The main qualitative conclusions, which are similar across the MS, can be understood from the UK simulations. The estimated proportion of households with ENEX10 in each country are reported in Figure 11; the Rol in 2009-10 had a noticeably lower proportion of households in ENEX10 (12.8\%) than the UK in 2012 (17.2\%) and France in 2010-11 (16.8\%), which reflects the higher total expenditure (income) in the Rol. Section 5.3.1 reports the impact of 
interventions on ENEX10 in the UK, while section 5.3.2 explains the factors influencing the impacts observed.

\subsubsection{The impact of interventions in the UK}

Figure 8 shows how the interventions alter ENEX10 in the UK. Since the target groups are relatively large (comprising up to a third of households), that most interventions have a small impact is telling. That high level metrics are difficult to move is one reason to question their use to assess policy effectiveness. This issue is worsened by high-level metrics being reliant on survey data and subject to sampling error. The $95 \%$ confidence interval for ENEX10 in the UK runs from $16.2 \%$ to $18.3 \%$. This means that many of the simulated interventions, while benefiting households on ground, would not result in ENEX10 moving by a sufficient amount for the movement to be identified as statistically significant.

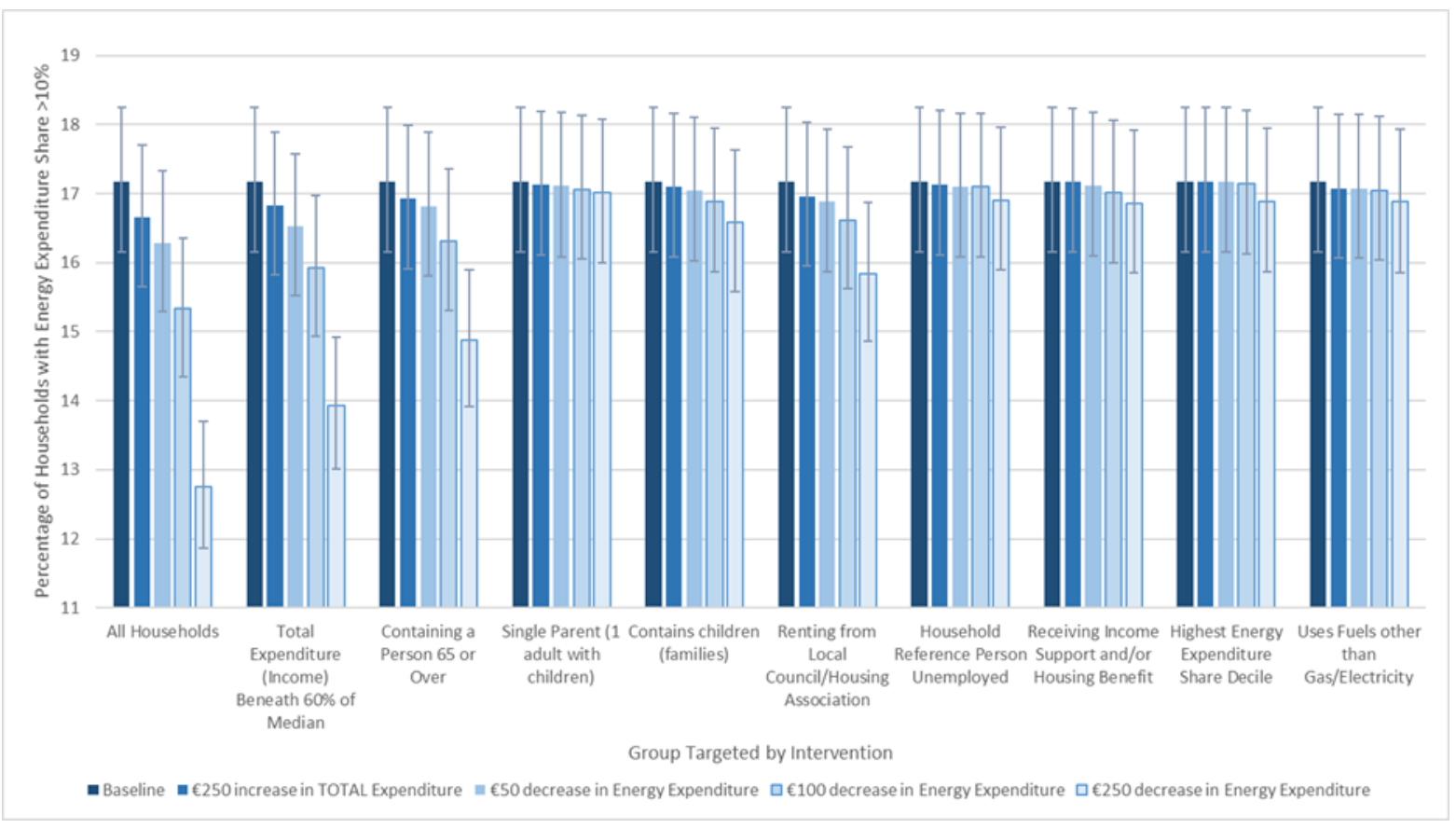

Figure 8: Interventions' impact on the percentage of UK households with an energy expenditure share exceeding 10\% in 2012 (whiskers represent 95\% confidence intervals) 
Figure 8 shows that if every household in the UK in 2012 had their ENEX reduced by $€ 250$, ENEX10 would fall by 4.4 percentage points. This also implies that if households in ENEX10 fuel poverty could be perfectly targeted, a $€ 250$ ENEX reduction would reduce ENEX10 by 4.4 percentage points. Targeting a $€ 250$ ENEX reduction at households with total expenditure beneath $60 \%$ of the median or at households containing at least one person aged 65 or over also produce relatively large falls in ENEX10 (decreases of 3.3 and 2.3 percentage points respectively).

Reducing ENEX has a far greater impact on ENEX10 than increasing total expenditure (income). Increasing all households' total expenditure by $€ 250$ reduces ENEX10 by less than 0.5 percentage points. The apparent poor performance of income transfers results from the denominator (total expenditure) being much larger than the numerator (ENEX) in the ratio forming ENEXShr. However, this is not a recommendation for ENEX reductions over income transfers. Standard microeconomic theory indicates that increasing a household's income should raise their welfare by the same, or greater amount, than increasing consumption of a particular good/service. While a fuel poor household will value free additional energy, they may value additional food even more.

Targeting interventions at households with the highest ENEXShr has a very limited impact on ENEX10. Reducing the ENEX of this group by $€ 250$ reduces ENEX10 by only 0.3 percentage points. This highlights that the $10 \%$ of UK households with the highest ENEXShr have ENEXShr which generally far exceed the ENEX10 threshold; the median ENEXShr of these households is $17.8 \%$.

\subsubsection{Explaining the impact of different interventions}

Four main factors determine the impact of an intervention on ENEX10: 
(i) the size of the group targeted,

(ii) the proportion of the target group in ENEX10 fuel poverty,

(iii) the proximity of these households' ENEXShr to the ENEX10 threshold, and

(iv) the total expenditure (income) of these households.

Appendix A reports relevant data on points (i) to (iii) across the UK, France and Rol.

Figure A1 reports the proportion households in each target group for the three MS studied.

Figure A1 shows that households with total expenditure beneath $60 \%$ of the median, households containing someone 65 or older and households with children are large groups in the UK with each comprising more than $24 \%$ of UK households. In contrast, single parent households, households receiving housing benefit and households with an unemployed household head each comprise less than $6 \%$ of UK households.

Figure $\mathrm{A} 2$ reports ENEX10 in each of the target groups. It is noticeable that in all target groups ENEX10 is less than $50 \%$. This highlights the challenge of targeting fuel poverty policies; for the data considered, targeting interventions using common high-level household identifiers results in the majority of resources going to households not in ENEX10 fuel poverty. While targeting fuel poverty interventions using high-level identifiers is problematic, more focussed approaches require fuel-poverty specific data which involves its own costs and challenges. ${ }^{47}$ Also, existing policies may be targeted according to high-level indicators. Most notably, the Winter Fuel Payment in the UK is fundamentally an age-related income benefit costing around f2bn per annum. ${ }^{48}$

\footnotetext{
${ }^{47}$ For example, see Fahmy et al (2011) and Dubois, U. (2012).

${ }^{48}$ See 'Winter Fuel Payments update', House of Commons Library, Monday, 26 June 2017, available at: http://researchbriefings.parliament.uk/ResearchBriefing/Summary/SN06019 (last accessed 6.12.2017).
} 
The proportion of households who are both in a target group and in ENEX10 identifies the maximum percentage point decrease in ENEX10 that could occur by targeting a specified household group. These maximum possible decreases are reported in Figure A3. In the UK the largest maximum decreases in ENEX10 are achievable by targeting low income or older households since these groups represent both a large section of the population and have high rates of ENEX10. In contrast, targeting households with children has a low maximum impact as although this group forms around $30 \%$ of households, only $10 \%$ experience ENEX10 fuel poverty.

Table A1 reports the median ENEXShr of the households in each target group who are in ENEX10 fuel poverty. By looking at the median, rather than mean, one can understand how close the mass of households in ENEX10 fuel poverty are to the ENEX10 threshold. However, the role of households' proximity to the ENEX10 threshold in determining interventions' impact is mediated by the total expenditure (income) of households. Suppose two households have an $11 \%$ ENEXShr, but household A) has total expenditure of $€ 20,000$ and household B) has total expenditure of $€ 40,000 .{ }^{49}$ To reduce the ENEXShr of household A) to $10 \%$ requires a $€ 200$ ENEX reduction, but for household B) it requires a $€ 400$ ENEX reduction. Hence, target groups with lower total expenditure among their fuel poor households will have a greater reduction in ENEX10 for a given monetary intervention, holding everything else constant.

In Figure 9 the 'effectiveness' metric is designed to summarise the influence of factors (ii) to (iv) on an interventions' impact on ENEX10. Note that even if the 'effectiveness' metric records a relatively high value, the magnitude of the reduction in ENEX10 may be very small.

\footnotetext{
49 This gives household A) ENEX of $€ 2,200$ and household B) ENEX of $€ 4,400$.
} 


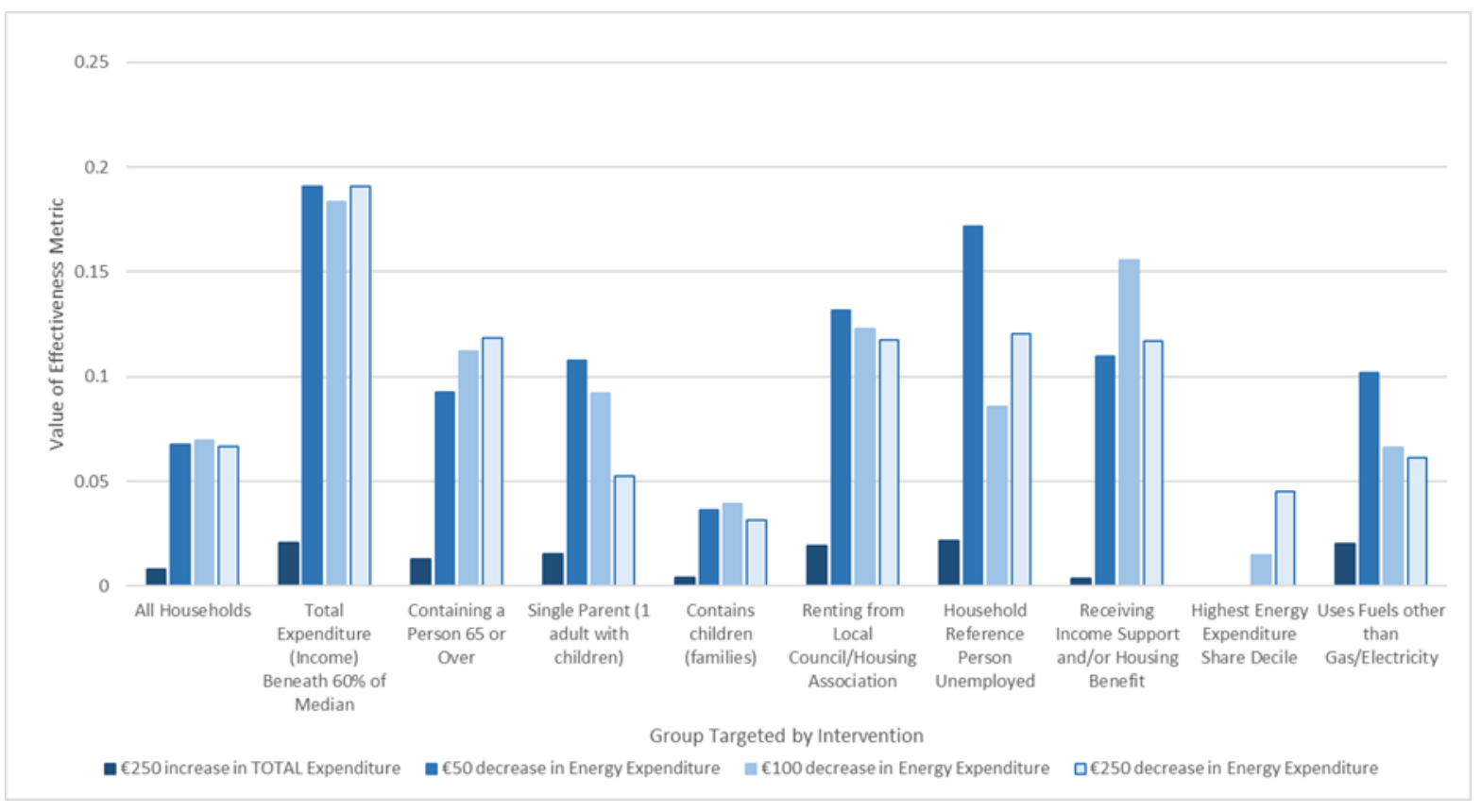

Figure 9: Effectiveness of interventions on reducing the percentage of UK households with an energy expenditure share exceeding 10\% in 2012

Figure 9 shows the most effective interventions in the UK are ENEX reductions targeted at low income households. That the ENEX reductions targeted at low income households have similar effectiveness indicates that the density of the ENEXShr distribution is fairly constant above the ENEX10 threshold for these households. The other relatively effective interventions are ENEX reductions targeted at: (i) households in social housing, (ii) where the household head is unemployed, and (iii) receiving income support or housing benefit. However, the limitations of targeting using high-level identifiers is illustrated by considering the value of the effectiveness metric if the interventions could be perfectly targeted, i.e. they reach all ENEX10 fuel poor households, but no households below the ENEX10 threshold. With perfect targeting, the ENEX reduction interventions all deliver an effectiveness metric of around 0.4 , roughly double the value of the most effective intervention in Figure 9. 


\section{Conclusions and Policy Implications}

\subsection{The Role of Energy Expenditure Share Distributions}

The simulations' main insight is that, if a policymaker wants to improve the picture of fuel poverty given by high-level ENEX metrics, understanding ENEXShr distributions among different household groups is valuable. Understanding the ENEXShr distribution has two impacts, one positive and one that can distort policy. The positive effect is to ensure a target group has a high proportion of fuel poor individuals. The potential distortion is that to achieve the greatest improvement in a high-level ENEX metric for the lowest cost it makes sense to target groups where there is mass of individuals lying just above the poverty threshold. The distorting influence of such an approach can be understood using Figure 10.

A)

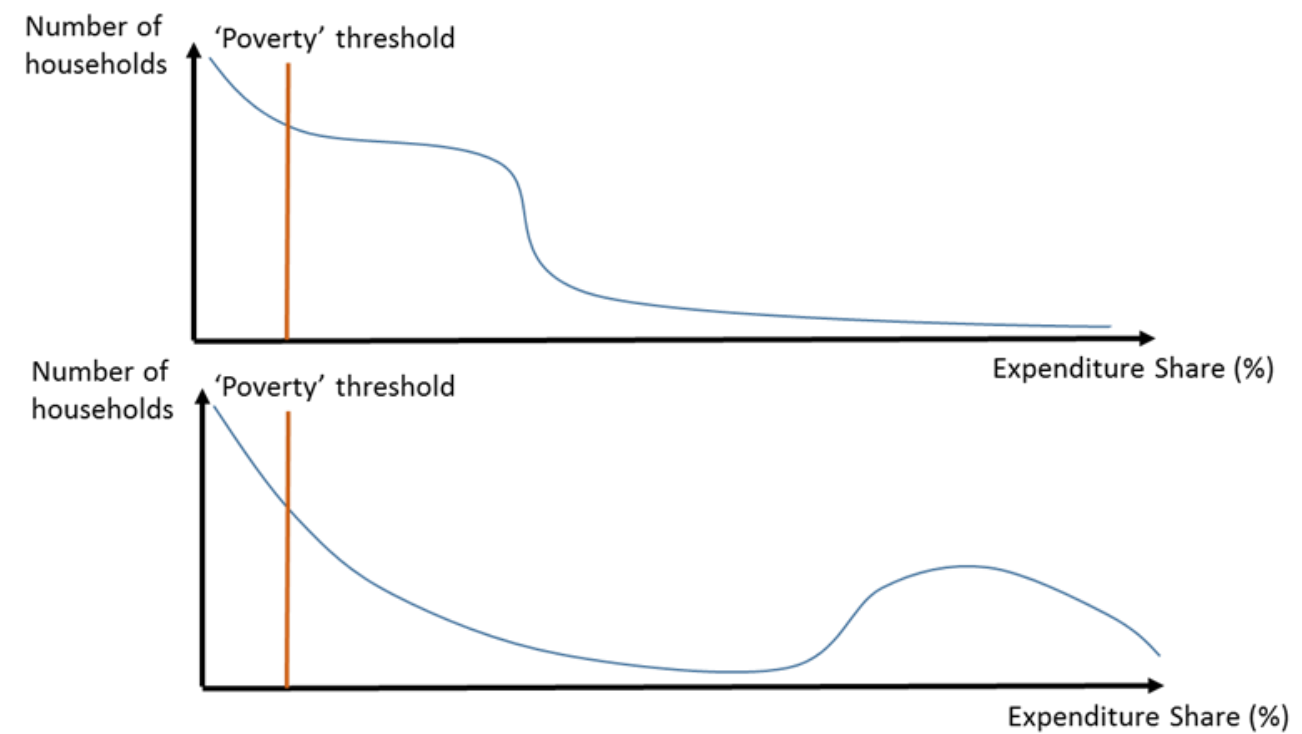

Figure 10: Alternative energy expenditure share distributions

Consider two groups A) and B) that have a similar proportion of households lying above the ENEXShr threshold, similar average total expenditures and involve households that respond in a similar way to a given intervention. $\ln A$ ) the majority of the fuel poor lie just above the poverty threshold, while in B) there is a large mass of households some distance above the 
threshold. In A), a cynical policymaker might choose interventions that reduce ENEX by only a small amount. This will noticeably reduce the fuel poverty rate at a relatively low cost, but will have limited impact on households in the deepest fuel poverty. Second, if A) and B) are alternative target groups, a policymaker focusing on high-level metrics would target A) as the fuel poverty rate could be reduced at a lower cost.

This distorting influence is potentially present for all headcount based ENEXShr metrics. Highlighting this distortion is not new, for example, Bourguignon and Fields (1990) note the issue in relation to income poverty, while Heindl (2013) notes it in relation to fuel poverty. However, the seriousness of this distortion is arguably lower for ENEX-based fuel poverty than income poverty. Whereas as income is an absolute figure, ENEXShr is a ratio and so, as noted in section 5.3.2, total expenditure influences the ability to reduce ENEXShr. That ENEXShr will be cheaper to reduce in groups with lower average total expenditure (income) reduces the risk that policies targeted to maximise reductions in ENEXShr-based fuel poverty metrics fail to reach households in the most pressing circumstances.

\subsection{Improving Self-Reported Lived Experience Indicators}

While section 6.1 highlights challenges with ENEX-based headcount metrics, the results in section 5.2 indicate further research is needed around the messages to take away from selfreports of the lived experience, such as EU-SILC data. For example, one could investigate if perceptions of energy affordability are influenced by political and media debates as well as actual changes in income, expenditure or housing conditions. That a discrepancy exists between households identified as fuel poor according to 'objective' ENEX indicators and 'subjective' lived experience indicators has been recognised by Waddams Price et al. (2012) and Scott et al. (2008). 
In future research it is important to investigate alternatives to the EU-SILC indicators: (a) the perceived ability to keep one's home adequately warm and (b) the presence of utility bill arrears. Tirado Herrero (2017) and Thomson et al. (2017) explain that both indicators are imperfect for energy affordability/fuel poverty assessment since (a) potentially suffers from an ambiguity of meaning and (b) is a 'noisy' indicator as it includes arrears on bills other than energy. Given that perception based questions are always likely to raise concerns around meaning, it seems important to collect data relating to specific and verifiable energy-focussed situations. The advantage of verifiable indicators is that, with sufficient resources, research could investigate biases from self-reporting. Also, verifiable situations should be specific enough to bring clarity and vividness to policy debates.

Below are five questions that possess at least one of the following advantages over indicators (a) or (b): (i) an energy specific focus, (ii) a clearly defined situation indicating affordability pressures, or (iii) a situation that could be verified:

1. In the last twelve months, has your household been unable to pay your heating, electricity or gas bill on time due to financial pressures?

2. In the last twelve months, has your electricity or gas supply been disconnected for the non-payment of bills?

3. In the past month, have you consciously restricted the use of energy in your home to ensure you had sufficient money to purchase food?

4. Consider the last time you spent money on energy, did you have to borrow money to make this payment/purchase?

5. Last winter were you forced to keep your home colder than you would like due to financial pressures? 
These questions are starting suggestions rather than final recommendations, for example, the time period to which the questions refer varies and this should be set according research/policy priorities. Referring to 12 months gives an overview of the year but may introduce recall issues. Referring to the past month reduces recall issues and introduces the potential for seasonality in responses related to the month(s) of interview. If all sampling is conducted in a single month/season this seasonality in response is undesirable, but if interviewing is performed throughout the year it could add to the richness of the data collected.

While a bespoke pan-EU energy affordability/fuel poverty survey ${ }^{50}$ would obtain the richest data, this is likely to be a costly exercise. A key advantage of EU-SILC style lived experience questions is that they can be easily introduced into existing surveys thereby minimising the cost of data collection. To calculate ENEX-based indicators considerable effort is required to collect data on households' total expenditure, income and/or dwelling characteristics. As a pragmatic first step to a better understanding of energy affordability/fuel poverty across the EU it seems important to collect data from questions similar in style to the five suggested above. Due to the existing EU-SILC indicators feeding into the long-run time series of material deprivation statistics in the $\mathrm{EU}^{51}$, the new indicators would add to, rather than supplant indicators (a) and (b). The funding of improved/additional data collection focusing specifically on energy affordability is an area where the EU could achieve real impact.

\subsection{A Policymaking Framework for Fuel Poverty}

\footnotetext{
${ }^{50}$ As argued for by Thomson et al (2017). Trinomics (2016) also explore options for energy poverty measurement in the EU.

${ }^{51}$ For example, see http://ec.europa.eu/eurostat/statisticsexplained/index.php/Material deprivation statistics - early results (last accessed 29.8.17).
} 
As illustrated in Figure 1, a wide range of fuel poverty/affordability metrics have been suggested beginning with Isherwood and Hancock (1979) and expanding greatly following Boardman (1991). Figure 11 shows how the choice of metric can significantly alter the recorded fuel poverty rate. In particular, the LIHC metric dramatically reduces the recorded fuel poverty rate in the UK, France and RoI. In the UK in 2012, the LIHC indicator ${ }^{52}$ more than halves the estimated fuel poverty rate compared to ENEX10, from $17.2 \%$ to $8.4 \%$. Yet, the main point of Figure 11 is that while the choice of metric alters the recorded fuel poverty rate, the economic positions and lived experiences of households remain unchanged. This highlights why an excessive emphasis on high-level fuel poverty metrics should be avoided. The choice of high-level metric only affects households' actual experience if policymaking processes are imperfect, so that changing the metric alters the resources available for fuel poverty alleviation or how these resources are allocated.

\footnotetext{
52 Compared to the UK's official LIHC indicator, the current analysis proxies household income with total expenditure, uses actual rather than required ENEX, does not equivalise total expenditure and does not deduct housing costs from total expenditure.
} 


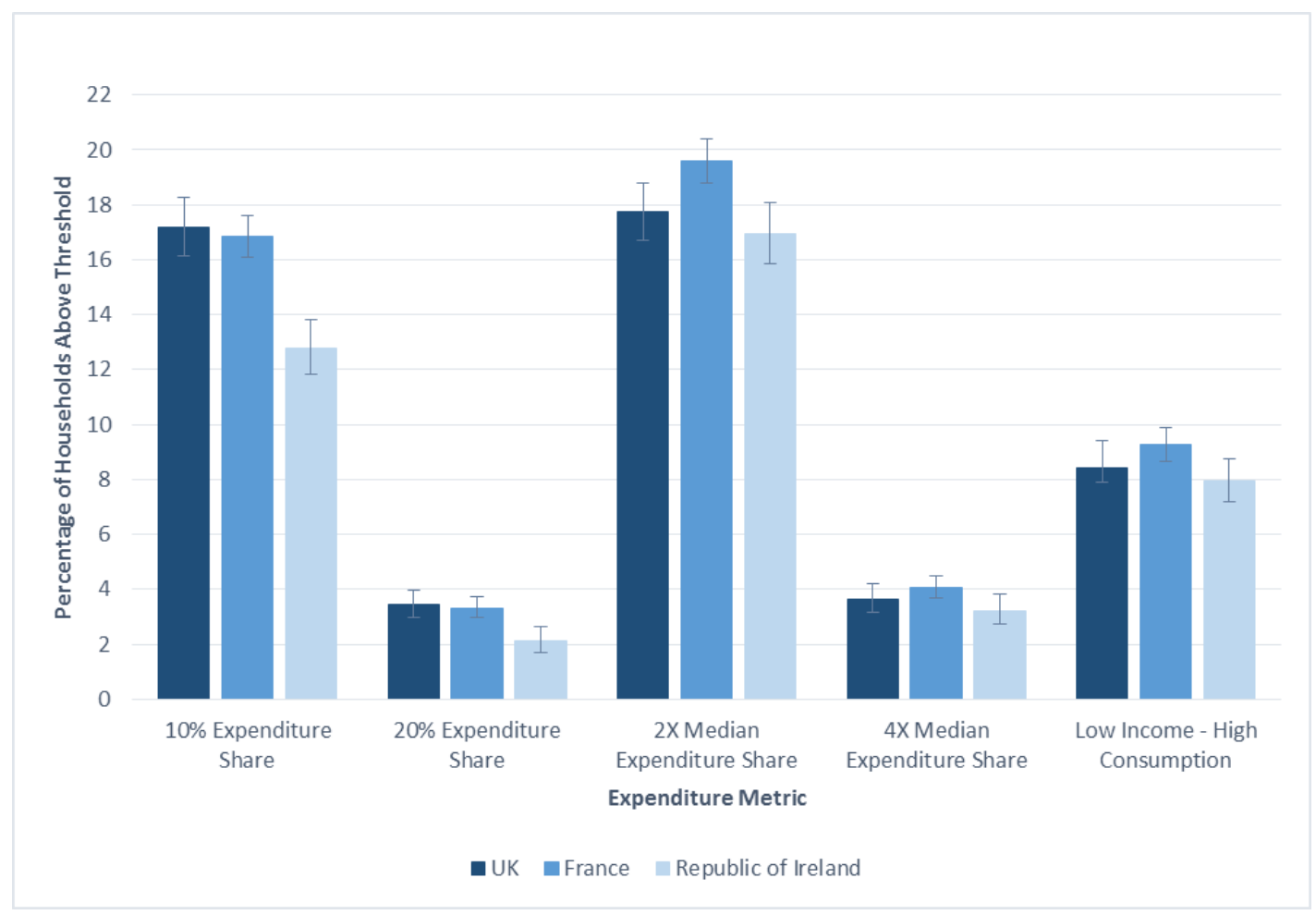

Figure 11: Percentage of households above alternative fuel poverty thresholds in the UK, France and Rol (whiskers show the $95 \%$ confidence interval)

All of the metrics identified in Figure 1 incorporate various value judgements and assumptions. Also, different metrics, and the concepts that lie behind them, may suit different tasks. For example, ENEX10 based on actual ENEX is useful for assessing changes in the political salience of energy affordability, but far from ideal for targeting interventions. In contrast, while the LIHC metric has issues as a high-level metric ${ }^{53}$, targeting resources at households with low income and high energy consumption seems reasonable. Rather than assessing policy performance via movements in high-level metrics, tracking estimates of total ENEX reductions/welfare gains achieved seems desirable. This implies greater weight should be given to collecting and improving studies evaluating alternative interventions.

${ }^{53}$ See Heindl and Schuessler (2015). 
Given the distributional choices inherent to fuel poverty alleviation, an idealised policymaking approach would be:

(i) Democratically elected representatives determine the resources for fuel poverty alleviation after assessing a broad range of evidence. ${ }^{54}$

(ii) Resources are allocated to interventions based on impact assessments identifying those delivering the greatest welfare improvements for a given cost.

Unfortunately, there are two issues with this neat split. First, selecting interventions by their effectiveness has implicit distributional effects by influencing which households receive support. Supporting particular interventions for distributional reasons, rather than on effectiveness grounds, could be legitimate as long as policymakers explicitly recognise the opportunity costs involved.

The second issue is whether the political process, and media debates, are sufficiently sophisticated to move away from a single headline metric to consider a range of evidence when assessing fuel poverty. Unfortunately, as Thomson et al. (2016) describe under 'path dependency', classifying a metric as 'official' can lead to it receiving undue attention, and political debates' sophistication cannot be guaranteed. In such a world the choice of 'official' fuel poverty definition, by altering the reported fuel poverty rate, may alter the resources allocated to fuel poverty alleviation.

\subsection{Assessing Interventions' Effectiveness}

While stressing the importance of evaluating individual interventions, executing these evaluations is not necessarily straightforward. First, the value of performing affordability

\footnotetext{
${ }^{54}$ This includes evidence on the relative merits of traditional income transfers relative to energy-specific interventions.
} 
specific assessments must be recognised and appropriate resources provided. It is not automatic that energy efficiency interventions maximising carbon savings are most effective for reducing fuel poverty/increasing energy affordability.

Furthermore, Deller and Waddams (2015e) highlight that assessments of energy efficiency investments rely heavily on assumptions. These assumptions fall into two categories: (i) those concerning incentives and market prices, and (ii) technical assumptions about the energy required to heat homes to an acceptable level. Estimates of financial savings based on engineering models should be treated with caution. For example, Fowlie et al. (2015) compare the predicted and actual financial returns to households receiving funds from the US's Federal Weatherization Assistance Program. Although the realised data showed a negative internal rate of return, the scheme's engineering models projected a positive return. One reason for estimated savings not being realised is that engineering models using 'ideal' temperatures can overstate pre-intervention energy costs if a household heats their home to a lower than 'ideal' temperature. A critical issue when assessing the 'under-heating' of homes is identifying where individuals prefer lower temperatures.

Given these challenges, the value of the EU collating impact evaluation studies not only comes from sharing information on effective interventions, but also from sharing best practice on the methodologies used to assess interventions. While collating impact evaluation studies should accelerate the identification and adoption of effective interventions, the extent of the policy synergies across MS suggested by Thomson et al. (2016) is unclear. When interpreting results from different MS, MS' differing circumstances need to be considered; it seems logical that learning will be greatest among MS with similar circumstances. 


\subsection{Final Remarks}

Eurostat's ENEXShr data highlights considerable variations in energy affordability between EU MS, with a particularly large divide between the EU15 and NMS. This divide, and the inherent linkage between fuel poverty and distributional concerns, means the identification of a common EU-wide fuel poverty metric is problematic.

Simulating policy interventions highlights the risks of placing excessive emphasis on high-level fuel poverty metrics. Instead, greater official attention should be given to assessing, and developing the tools to assess, the welfare gains that specific interventions deliver. Collecting data on variations in energy affordability, identifying effective fuel poverty interventions and disseminating this knowledge are appropriate roles for the EU that should ensure the resources for fuel poverty alleviation achieve maximum impact.

\section{Appendix A - Explaining the Impact of Interventions}

Regarding household characteristics, median household expenditure in the Rol in 2009-10 was around a third higher than in the UK in 2012 and approximately 50\% higher than France in 2010-11. Second, Figure A1 shows the Rol had a far higher proportion of households using alternative fuels, i.e. utilising fuels other than gas and electricity than the UK ( $53.3 \%$ vs $7.4 \%$ ). The higher percentage of Irish households using alternative fuels corresponds to this indicator being less effective for targeting high ENEX households: in the UK households using alternative fuels had the second highest ENEX10, while in the Rol these households had only the sixth highest ENEX10. Third, the Rol had a younger age profile than the UK: the percentage of households containing someone aged 65 or over was 10 percentage points lower in the Rol, while the percentage of households with children was 10 percentage points higher. 
Some target groups are defined differently in the French dataset. Older households in France are identified by the head of the household being aged 65 or over rather than a household containing at least one person aged 65 or over. Furthermore, the percentage of households receiving 'housing benefit' in France was over $18 \%$ compared to less than $4 \%$ in the UK suggesting the policies referred to as 'housing benefit' were rather different.

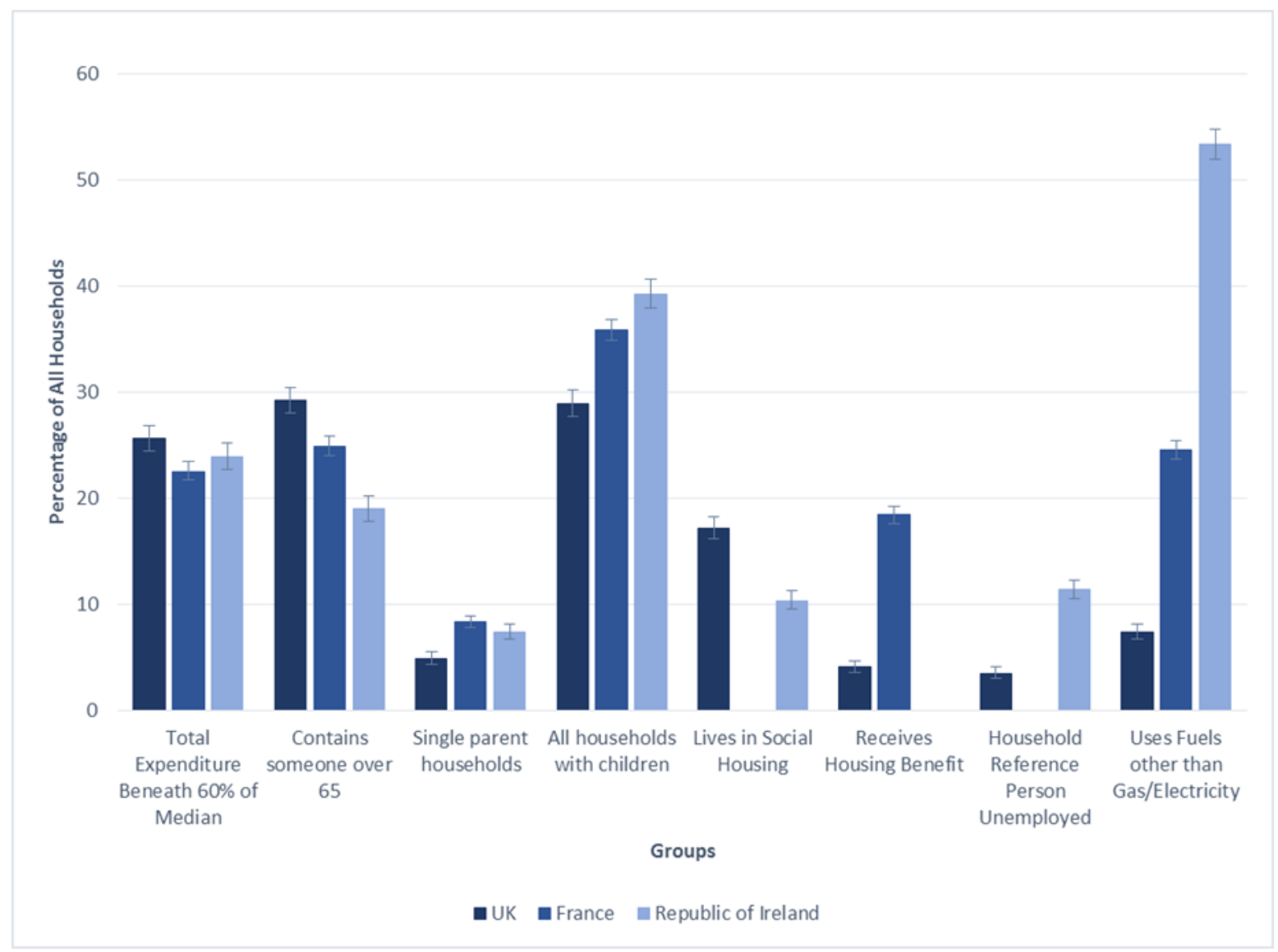

Figure A1: The percentage of households in the French, UK and Irish datasets in particular target groups $^{55}$ (whiskers represent $95 \%$ confidence intervals)

The percentage of each target group in ENEX10 fuel poverty is reported in Figure A2. In all three MS households with total expenditure below $60 \%$ of the median have the highest central estimate of ENEX10 fuel poverty. Comparing Figure A1 and Figure A2 the proportion

\footnotetext{
${ }^{55}$ The definitions of groups can vary between the MSs. Where no bar is present a dataset did not contain an appropriate group identifier.
} 
of households using fuels other than mains gas and electricity in ENEX10 fuel poverty appears inversely related to the percentage of households using alternative fuels. In the UK $41 \%$ of households using alternative fuels were in ENEX10 fuel poverty compared to only $16 \%$ in the Rol.

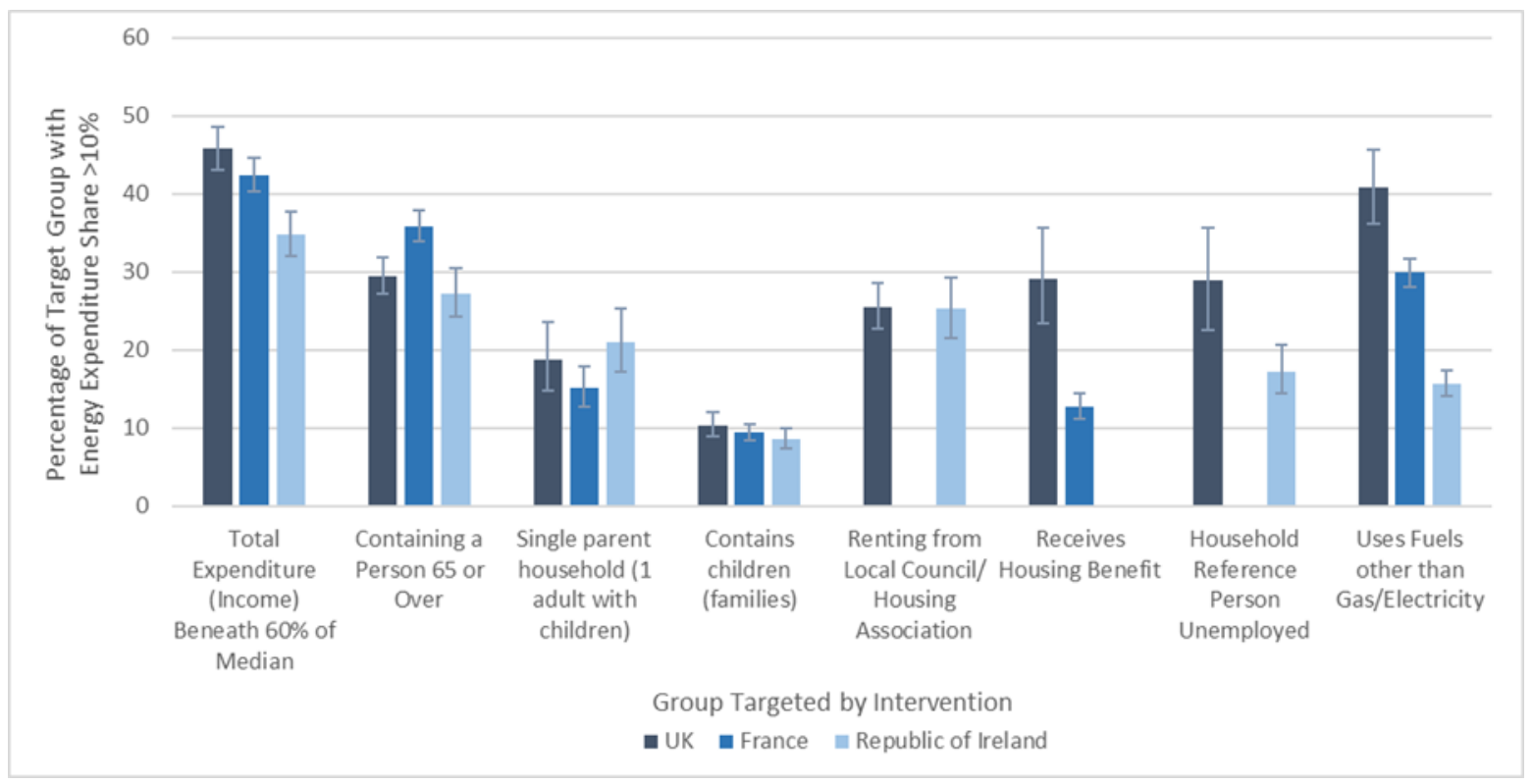

Figure A2: The percentage of households in target groups who have an energy expenditure share exceeding $10 \%$ (whiskers represent $95 \%$ confidence intervals)

Figure $A 3$ combines the information in Figures $A 1$ and $A 2$ to report the proportion of all households who are in a target group and in ENEX10 fuel poverty. Hence, Figure A3 shows the maximum possible decrease in ENEX10 by targeting each household group. In the Rol, compared to the UK and France, it is noticeable that targeting households using alternative fuels allows a greater ENEX10 reduction than targeting elderly households. 


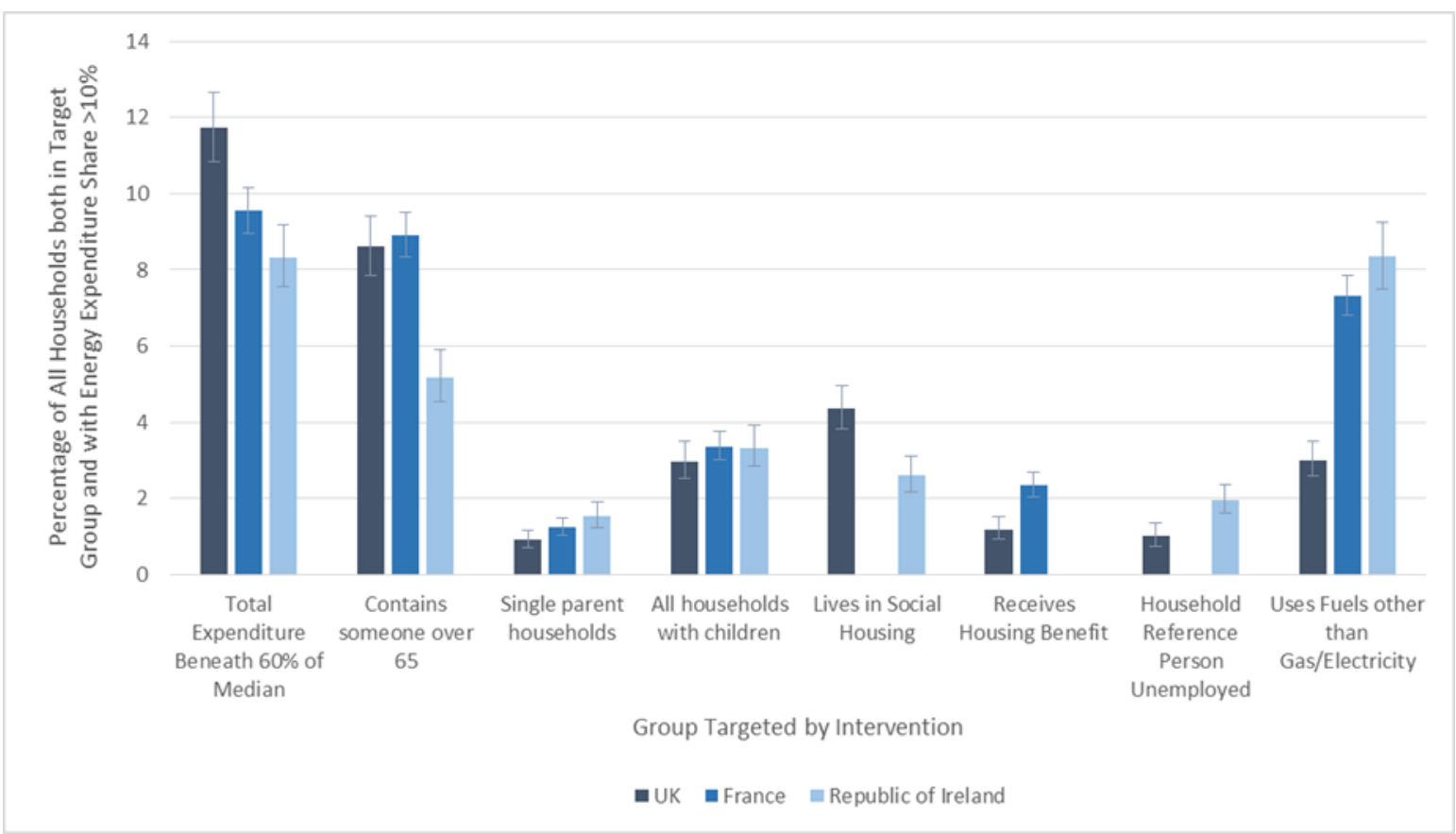

Figure A3: The percentage of all households in a target group and with an energy expenditure share exceeding $10 \%$ (whiskers represent $95 \%$ confidence intervals)

Table A1 gives an indication of the proximity of households in each target group to the ENEX10 threshold. Overall, the estimated median ENEXShr of households in ENEX10 fuel poverty is fairly similar across the three MS, except when comparing households with an unemployed head or households in the highest ENEXShr decile between the UK and Rol. It is apparent that the proximity of a target group's mass of ENEXShr to the ENEX10 threshold by itself does not determine an intervention's 'effectiveness' by comparing Table A1 with Figure 9. Considering the UK, households with children have the closest median ENEXShr to the ENEX10 threshold, while low income households have the third highest median ENEXShr. However, Figure 9 shows that reducing ENEX among low income households is the most 'effective' intervention, while targeting households with children is among the least 'effective' interventions. 


\begin{tabular}{c|ccc} 
Target Group & UK & France & Republic of Ireland \\
\hline Whole Population & 14.0 & 13.8 & 13.8 \\
Total Expenditure Beneath 60\% of Median & 15.4 & 15.4 & 14.8 \\
Contains a person 65 or over & 14.4 & 14.7 & 14.7 \\
Single parent (1 adult with children) & 14.1 & 13.6 & 13.6 \\
All households with children & 13.1 & 12.9 & 12.8 \\
Lives in Social Housing & 14.6 & - & 13.9 \\
Receives Housing Benefit & 13.9 & 13.7 & - \\
Household Reference Person Unemployed & 16.6 & - & 13.5 \\
Uses Fuels other than Gas/Electricity & 15.1 & 14.4 & 13.6 \\
Highest Energy Expenditure Share Decile & 17.8 & 17.1 & 15.1
\end{tabular}

Table A1: Central estimates of the median energy expenditure share (\%) of the subset of households that have energy expenditure shares exceeding $10 \%$ by household group

Last, Table A2 give central estimates for the total cost of the interventions targeting each high-level household group. That the figures for the Rol are far lower than for France or the UK simply results from the Rol containing fair fewer households.

\begin{tabular}{c|ccc} 
Target Group & UK & France & Republic of Ireland \\
\hline Whole Population & 7,167 & 7,142 & 436 \\
Total Expenditure Beneath 60\% of Median & 1,834 & 1,608 & 104 \\
Contains a person 65 or over & 2,092 & 1,778 & 83 \\
Single parent (1 adult with children) & 350 & 593 & 32 \\
All households with children & 2,072 & 2,560 & 171 \\
Lives in Social Housing & 1,229 & - & 45 \\
Receives Housing Benefit & 251 & - & 49 \\
Household Reference Person Unemployed & 295 & 1,315 & - \\
Uses Fuels other than Gas/Electricity & 717 & 1,750 & 232 \\
Highest Energy Expenditure Share Deceile & 529 & 714 & 44
\end{tabular}

Table A2: Central estimates of the cost $(€ \mathrm{~m})$ of transferring $€ 250$ to each of the households in the specified target groups in 2017 prices

\section{Appendix B - Differences in interventions' 'effectiveness'}

In Figures B1 and B2 the impact of interventions on ENEX10 in, respectively, the Rol and France are reported. Broadly speaking the results are similar to those for the UK in Figure 8. 
The largest difference between the UK and the other two MS, is that in the Rol and France targeting households using alternative fuels has a greater impact on the central estimate of ENEX10.

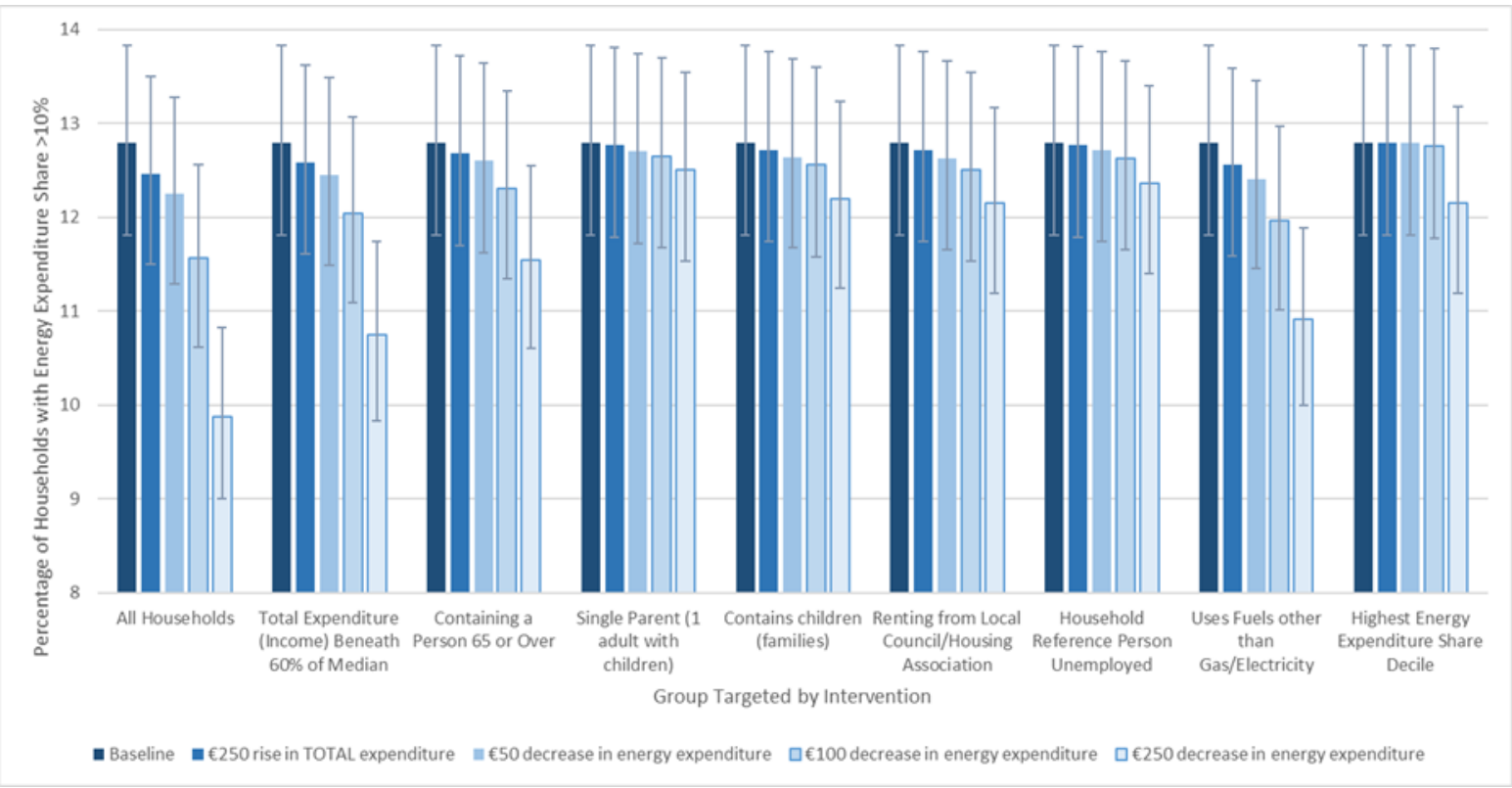

Figure B1: Interventions' impact on the percentage of Irish households with an energy expenditure share exceeding $10 \%$ in $\mathbf{2 0 0 9 - 1 0}$ (whiskers represent $95 \%$ confidence intervals) 


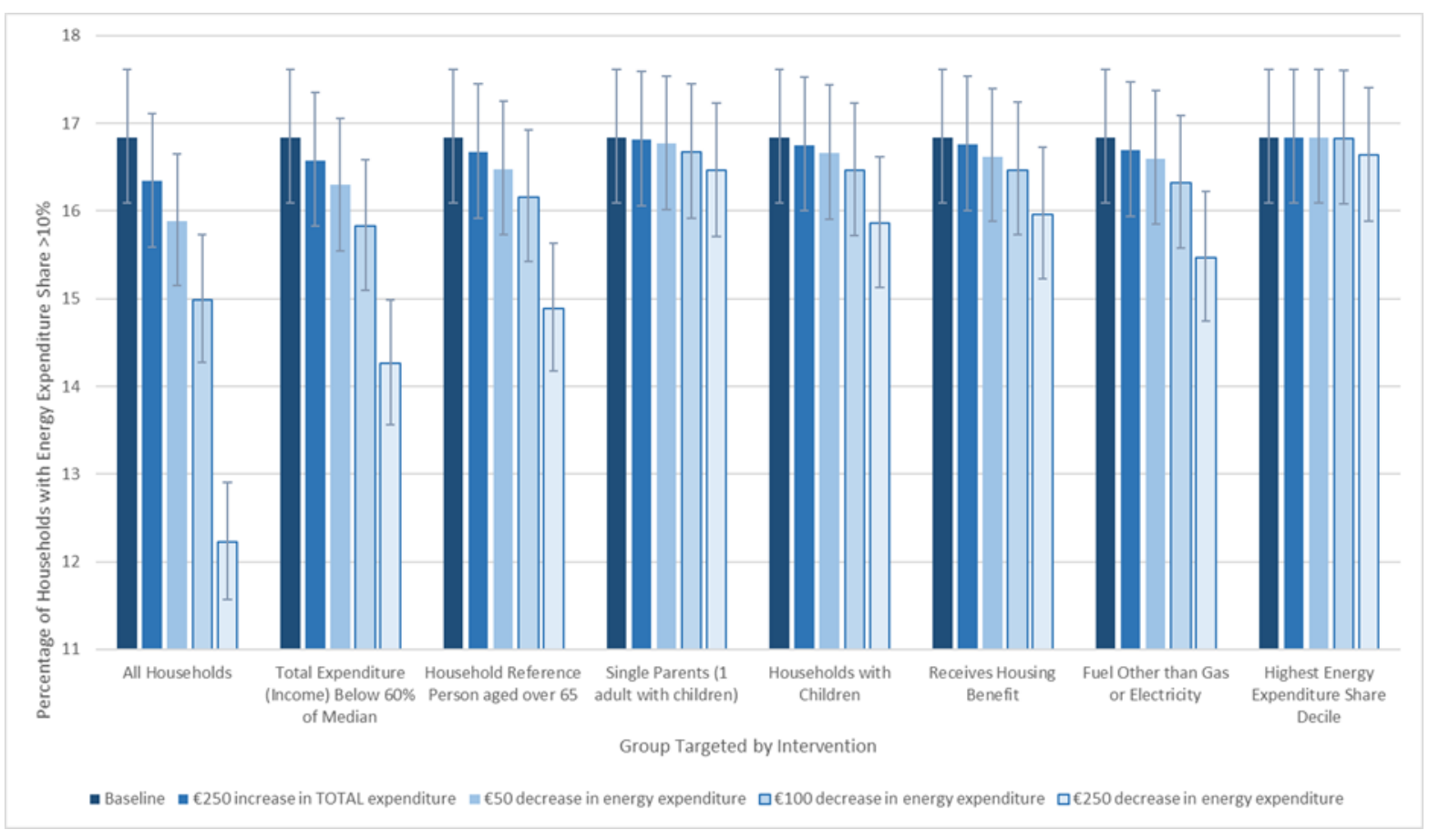

Figure B2: Interventions' impact on the percentage of French households with an energy expenditure share exceeding $10 \%$ in $\mathbf{2 0 1 0 - 1 1}$ (whiskers represent $95 \%$ confidence intervals)

Considering Figures 9, B3 and B4, in all three MS the most effective interventions are ENEX reductions targeted at low income households. Similarly, in all three MS targeting older households is moderately effective, with the targeting power of these households appearing strongest (relative to other target groups) in the Rol. In the Rol targeting households in social housing is roughly as effective as targeting low income households and more effective than targeting the unemployed. Another feature of the Rol is that targeting a $€ 250$ ENEX reduction at households with the highest ENEXShr is, relative to other interventions, reasonably effective. 


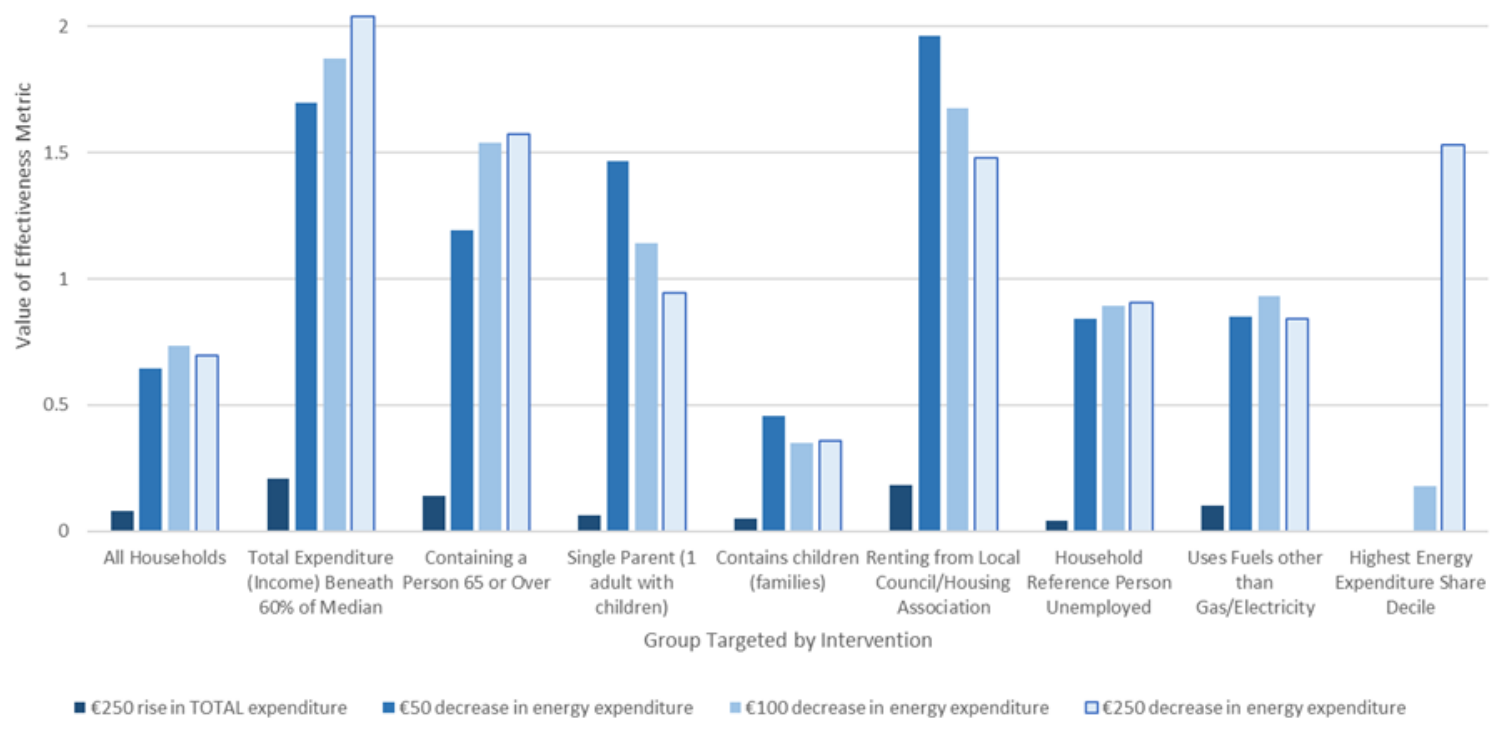

Figure B3: Effectiveness of interventions on reducing the percentage of Irish households with an energy expenditure share exceeding $10 \%$ in $2009-10$

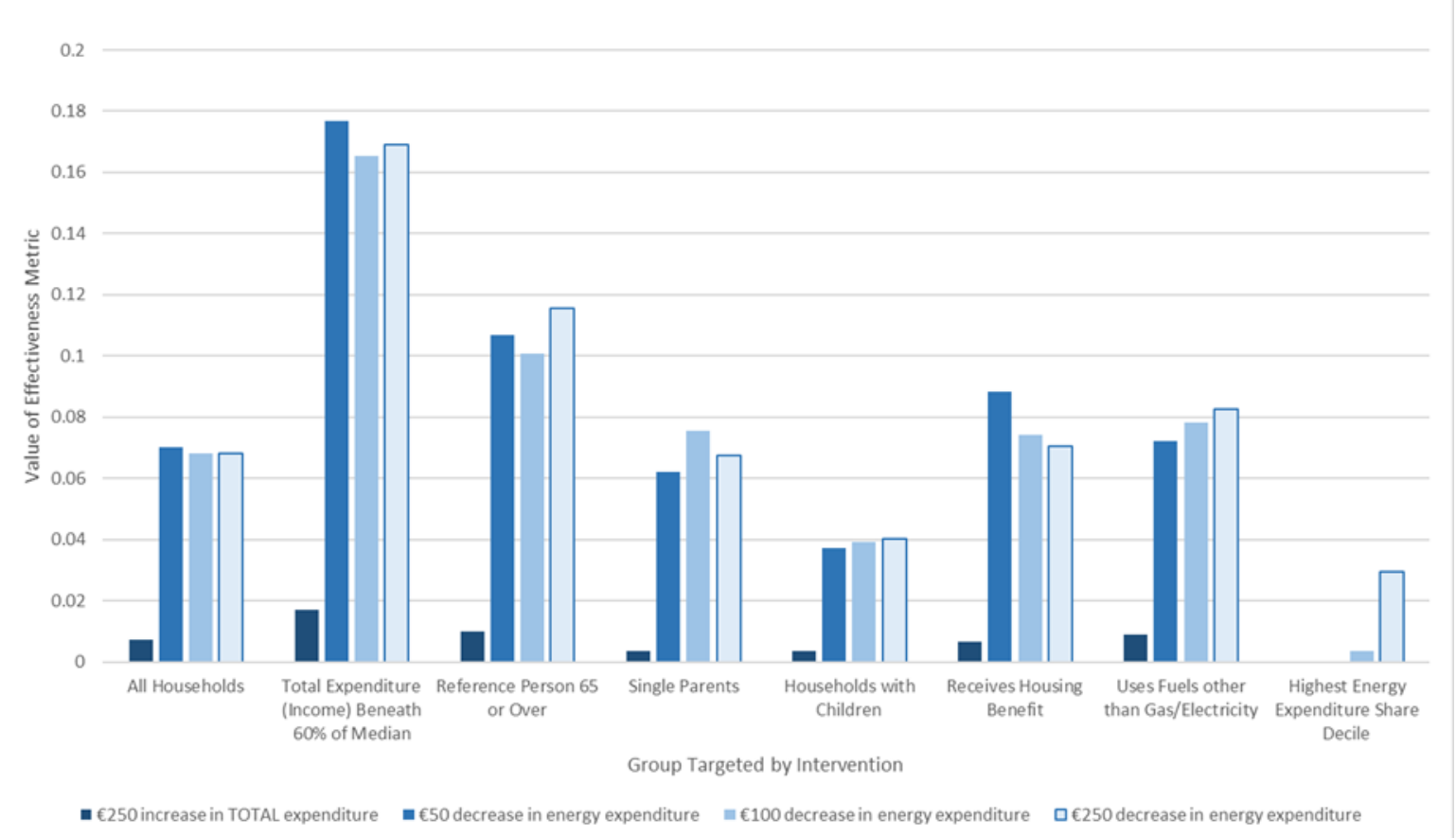

Figure B4: Effectiveness of interventions on reducing the percentage of French households with an energy expenditure share exceeding $10 \%$ in $2010-11$ 


\section{Acknowledgements}

The financial support provided by Microsoft, EDF Energy, the Utility Regulator Northern Ireland and E-Control, the Austrian energy regulator, through the Centre on Regulation in Europe (CERRE) is gratefully acknowledged. The author thanks participants at a CERRE workshop and a DG Ener presentation for their comments, in particular, Claire Milne. Catherine Waddams is thanked for her leadership of the CERRE project and valuable comments. The reviewers of this article are thanked for their insightful suggestions, in particular regarding the discussion and presentation of the simulation results. Also, the comments provided by CERRE project sponsors were valued.

\section{References}

Advani, A., P. Johnson, A. Leicester and G. Stoye, 2013. Household Energy Use in Britain: A Distributional Analysis. IFS Report R85, Institute for Fiscal Studies, London.

Boardman, B., 1991. Fuel poverty - from cold homes to affordable warmth. Belhaven Press, London.

Bourguignon, F. and G. S. Fields, 1990. Poverty measures and anti-poverty policy. Recherches Economique de Louvain, 56(3-4), pp. 409-427.

Bouzarovski, S., S. Petrova and R. Sarlamanov, 2012. Energy poverty policies in the EU: A critical perspective. Energy Policy, 49, pp. 76-82.

Bouzarovski, S. and S. Tirado Herrero, 2015. The energy divide: Integrating energy transitions, regional inequalities and poverty trends in the European Union. European Urban and Regional Studies, 24(1), 69-86. 
Brewer, M. and C. O'Dea, 2012. Measuring living standards with income and consumption: evidence from the UK. ISER Working Paper Series No. 2012-05, Institute of Social and Economic Research, Colchester, Essex.

Council of European Energy Regulators (CEER), 2014. The implementation of the 2020 Vision for Europe's energy customers by its supporters. CEER report C14-SC-20-03, Brussels.

Deller, D., 2016. Energy Affordability in the EU: The Risks of Metric Driven Policies. Centre for Competition Policy (CCP) Working Paper 16-9, University of East Anglia, Norwich.

Deller, D. and C. Waddams, 2015a. Affordability of utilities' services: extent, practice, policy. Centre for Regulation in Europe (CERRE) report, Brussels.

Deller, D. and C. Waddams, 2015b. Research Paper 4: Simulations of Policies to Alleviate Utility Affordability Issues in the UK: Evidence from the Living Costs and Food Survey 2012. Centre for Regulation in Europe (CERRE) report, Brussels.

Deller, D. and C. Waddams, 2015c. Research Paper 8: Simulations of Policies to Alleviate Utility Affordability Issues in France: Evidence from the 'Budget de Famille' Survey 2010-11. Centre for Regulation in Europe (CERRE) report, Brussels.

Deller, D. and C. Waddams, 2015d. Research Paper 5: Simulations of Policies to Alleviate Utility Affordability Issues in the Republic of Ireland: Evidence from the Irish Household Budget Survey 2009-10. Centre for Regulation in Europe (CERRE) report, Brussels.

Deller, D. and C. Waddams, 2015e. Research Paper 13: Review of Evidence on the Effectiveness of Policies Tackling Fuel Poverty and Digital Exclusion. Centre for Regulation in Europe (CERRE) report, Brussels. 
Deller, D. and C. Waddams, 2017. Report into UK Energy Expenditure Shares - A Long Term View. Centre for Competition Policy (CCP) report, University of East Anglia, Norwich.

Dubois, U., 2012. From targeting to implementation: The role of identification of fuel poor households. Energy Policy, 49, pp. 107-115.

European Commission, 2010. An Energy Policy for Consumers. Commission Staff Working Paper SEC(2010) 1407 final, Brussels.

Eurostat, 2015. Household Budget Survey, 2010 Wave - EU Quality Report. DOC HBS/2015/01/EN, Version 2, Brussels.

Fahmy, E., D. Gordon and D. Patsios, 2011. Predicting fuel poverty at a small-area level in England. Energy Policy, 39(7), pp. 4370-4377.

Fowlie, M., M. Greenstone and C. Wolfram, 2015. Do Energy Efficiency Investments Deliver? Evidence from the Weatherization Assistance Program. NBER Working Paper Series, Working Paper 21331. Cambridge, Massachusetts.

Healy, J.D. and J.P. Clinch, 2002. Fuel poverty in Europe: A cross-country analysis using a new composite measurement. Environmental Studies Research Series Working Paper ESRS 02/04, University College Dublin, Dublin.

Heindl, P., 2013. Measuring fuel poverty: General considerations and application to German household data. ZEW Discussion Papers No. 13-046, Mannheim.

Heindl, P. and R. Schuessler, 2015. Dynamic properties of energy affordability measures. Energy Policy, 86, pp. 123-132. 
Hills, J., 2012. Getting the measure of fuel poverty - Final Report of the Fuel Poverty Review. CASE report 72, Centre for Analysis of Social Exclusion. London.

Isherwood, B.C. and R.M. Hancock, 1979. Household Expenditure on Fuel: Distributional Aspects. Economic Advisor's Office, Department for Health and Social Security, London.

Ofgem, 2015. Consumer Vulnerability Strategy Progress Report. London.

Poggi, A. and M. Florio, 2010. Energy deprivation dynamics and regulatory reforms in Europe: Evidence from household panel data. Energy Policy, 38, pp. 253-264.

Scott, S., S. Lyons, C. Keane, D. McCarthy and R. Tol, 2008. Fuel poverty in Ireland : Extent, affected groups and policy issues. Economic and Social Research Institute working paper No. 262, Dublin.

Thomson, H. and C. Snell, 2013. Quantifying the prevalence of fuel poverty across the European Union. Energy Policy, 52, pp. 563-572.

Thomson, H., S. Bouzarovski and C. Snell, 2017. Rethinking the measurement of energy poverty in Europe: A critical analysis of indicators and data. Indoor and Built Environment, 26(7), pp. 879-901.

Thomson, H., C. Snell and C. Liddell, 2016. Fuel poverty in the European Union: a concept in need of definition?. People, Place and Policy, 10(1), pp. 5-24.

Tirado Herrero, S., 2017. Energy poverty indicators: A critical review of methods. Indoor and Built Environment, 26(7), pp. 1018-1031.

Trinomics, 2016. Selecting Indicators to Measure Energy Poverty - Final Report. Report for DG-Ener, ENER/B3/507-2015, Rotterdam. 
Waddams Price, C., K. Brazier and W. Wang, 2012. Objective and subjective measures of fuel poverty. Energy Policy, 49, pp. 33-39. 